\title{
ESTUDOS DE MINERAIS OPACOS E SUSCETIBILIDADE MAGNÉTICA NOS GRANITOS MUSA E JAMON (REGIÃO DE RIO MARIA - SE DO PARÁ) E SUAS IMPLICAÇÕES PETROLÓGICAS
}

\author{
MARÍLIA S. MAGALHÃES* \& ROBERTO DALL'AGNOL* (**)
}

\begin{abstract}
OPAQUE MINERAL AND MAGNETIC SUSCEPTIBILITY STUDIES IN MUSA AND JAMON GRANITES (RIO MARIA REGION - SOUTHEASTERN OF PARÁ) AND THEIR PETROLOGICAL IMPLICATIONS. Musa and Jamon granites represent Lower Proterozoic anorogenic magmatism of the Central Amazonian Province. Magnetite (Mt), ilmenite (Ilm), hematite (Ht) and goethite (Gt) are the opaque oxide minerals observed. Pyrite (Py) is the only sulfide described. Three Em types are distinguished: individual (I) Ilm - isolated crystals, composite (C) Ilm - crystals joinned to Mt, and trellis (T) Ilm - lamellae developped into the Mt. Titanomagnetite (TMt), I and C Ilm were the first crystallizing opaque minerals. Later, I Ilm was partially destabilized by titanite. During the subsolidus stage the oxidation-exsolution of TMt occurred, transforming this oxide into $\mathrm{Mt}+\mathrm{T} \mathrm{Ilm}$. Partial hematitization of Mt and oxyhydration (Gt formation) had also occurred during this stage. Magnetic susceptibility (MS) values of the granites are high, and decrease with magmatic differentiation (amphibole facies $\rightarrow$ biotite facies $\rightarrow$ leucogranites). The high Mt contents justify the high MS values. Positive correlations among MS and modal contents of opaques, amphibole and the total of mafic minerals show that the earliest facies have the highest contents of the mentioned minerals, as well as of Mt. On the other hand, negative correlation is observed between chlorite (deuteric phase) and MS. Chlorite is enriched in the later facies in which the transformations are very important and the $\mathrm{Mt}$ is partially destabilized to $\mathrm{Ht}$. Positive correlations are also observed among $\mathrm{MS}$ and $\mathrm{Fe}_{2} \mathrm{O}_{3}, \mathrm{FeO}, \mathrm{MgO}$ and $\mathrm{TiO}_{2}$ contents. The above characteristics and the $\mathrm{Fe}_{2} \mathrm{O}_{3} / \mathrm{FeO}$ ratios, generally high or near to one, allows to classify these granites into the $\mathrm{Mt}$ series. The titanite $+\mathrm{Mt}+$ quartz association and $\mathrm{Fe}_{2} \mathrm{O}_{3} / \mathrm{FeO}$ ratios indicate that relatively oxidizing conditions, probably, $\mathrm{fO}_{2}$ conditions near to $\mathrm{Ni}-\mathrm{NiO}$ buffer, prevailed during the evolution of Musa and Jamon granites.
\end{abstract}

Keywords: Granites, opaque minerals, magnetic susceptibility, oxygen fugacity, typology.

\begin{abstract}
RESUMO Os Granites Musa e Jamon são exemplos do magmatismo anorogênico que se desenvolveu de forma expressiva no Proterozóico Inferior da Província Amazônia Central. Os minerais opacos observados nesses granitos foram magnetita $(\mathrm{Mt})$, ilmenita $(\mathrm{Ilm})$, hematita $(\mathrm{Ht})$, goethita $(\mathrm{Gt})$ e pinta $(\mathrm{Pi})$. Ilm pode ocorrer como três tipos texturais: cristais isolados denominados Ilm individual (I), cristais em contato com Mt - Em composite (C) e lamelas na Mt - um trellis (T). Magnetita com Ti (TMt), Ilm I, Ilm C e Pi foram os primeiros minerais opacos que se cristalizaram. No estágio magmático, ocorreu a desestabilizacão parcial de Ilm por titanita. Ainda no estágio subsolidus, TMt foi transformada a Mt + Ilm T devido ao processo de exsolução-oxidação. Hematitização parcial de Mt e formação de Gt também ocorreram no estágio subsolidus. Estes granitos são caracterizados por valores elevados de suscetibilidade magnética (SM), que decrescem no sentido da diferenciação magmática (fácies com anfibólio $\rightarrow$ fácies com biotita $\rightarrow$ leucogranitos). O conteúdo expressivo de Mt justifica os valores elevados de SM. Correlações positivas entre SM e conteúdos modais de minerais opacos, anfibólio e total de máficos demonstram que as fácies geoquimicamente menos evoluídas apresentam os conteúdos mais elevados de Mt. De outra forma, a correlação negativa entre SM e clorita é coerente, uma vez que clorita é uma fase enriquecida nas fácies formadas mais tardiamente, cujas transformações tardi a pós-magmáticas foram mais intensas e causaram a desestabilização parcial de Mt a Ht. Correlações positivas entre $\mathrm{SM} \mathrm{e} \mathrm{Fe}_{2} \mathrm{O}_{3}, \mathrm{FeO}, \mathrm{MgO}$ e $\mathrm{TiO}_{2}$ ratificam o comportamento comentado entre $\mathrm{SM}$ e composição mineral. As características apresentadas e as razões $\mathrm{Fe}_{2} \mathrm{O}_{3} / \mathrm{FeO}$, geralmente elevadas ou próximas a um $(1,0)$, permitem classificar estas rochas como granitos da série a Mt. A associação mineral titanita+Mt+quartzo e as razões $\mathrm{Fe}_{2} \mathrm{O}_{3} / \mathrm{FeO}$ indicam que condições relativamente oxidantes, com provável fO $\mathrm{f}_{2}$ próximo ao do tampão $\mathrm{Ni}-\mathrm{NiO}$, foram importantes durante a evolução dos granitos Musa e Jamon.
\end{abstract}

Palavras-chaves: Granitos, minerais opacos, suscetibilidade magnética, fugacidade de oxigênio, tipologia.

INTRODUCẼ̃O Os Granitos Musa e Jamon, situados na região de Rio Maria no sudeste do Estado do Pará, representam plútons do Proterozóico Inferior $(1883+5 /-2 \mathrm{Ma}$, U-Pb em zircões do Granito Musa, Machado et al 1988 e $1601 \pm 2$ Ma, método isocrônico Rb-Sr no Granito Jamon, Dall'Agnol et al 1984), que intrudem o metatonalito gnáissico Arco-Verde (Althoff et al. 1991), rochas metavulcanossedimentares (Supergrupo Andorinhas, DOCEGEO 1988) e o Granodiorito Rio Maria (Fig. 1), todas estas unidades de idade arqueana.

O Granito Musa foi parcialmente delimitado por Cordeiro et al. (1982, 1984). Dall'Agnol et al (1986), Gastal (1987,
1988) e Gastal et al (1987) discutiram aspectos petrológicos e geocronológicos desse maciço, que é considerado, - como o Granito Jamon, - um representante do magmatismo anorogênico da Província Amazônia Central (Dall'Agnol et al 1986) ou granito pós-tectônico (Gastal 1988).

O Granito Jamon foi intensamente estudado, no decorrer da última década. Detalhes sobre a geologia desse maciço podem ser obtidos em Dall'Agnol (1982,1987).

Em continuidade às pesquisas petrológicas, foi elaborado este trabalho com o objetivo de definir a partir de dados de suscetibilidade magnética (SM) e minerais opacos, em conjunto

\footnotetext{
* Centro de Geociências, Departamento de Geoquínica e Petrologia, Universidade Federal do Pará, Caixa Postal 1611, CEP 66075-900, Guamá, Belém, Pará, Brasil ** Pesquisador do CNPq
} 

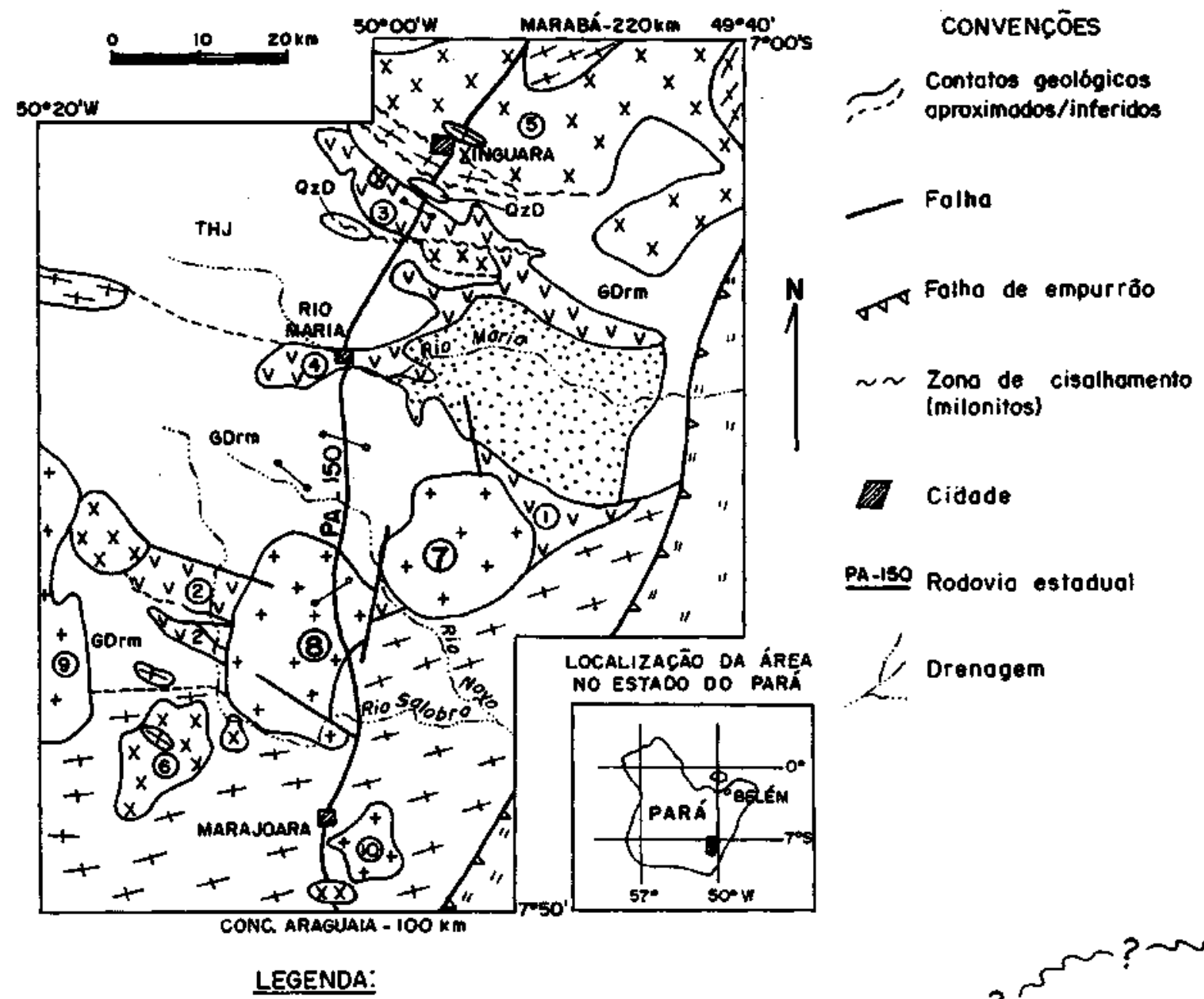

PA-130 Rodovio estodual

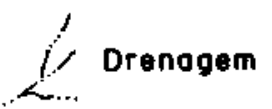

[2:- Foixo de Dobramentos Aroguoio.

Grupo Rio Fresco
Sedimentos delíticos, clásticos e quimicos, onquimetomorficos.

Leucomonzogranitos o biotito. 5 xinguoro; 6 Moto-surróo.

V "Greenstone belts"

I bobogu / Logoo Seco; 2 Pedra Preto; 3 Identidode; 4 Serrinho.

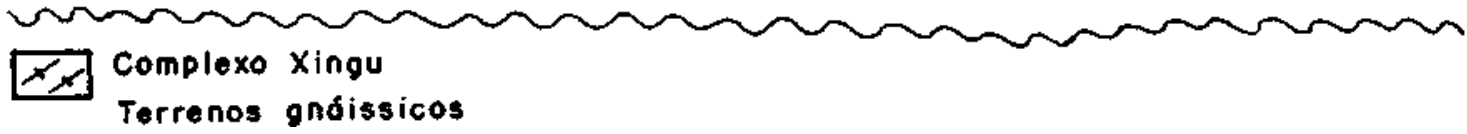

Figura 1 - Mapa geológico da região de Rio Maria e proximidades (sudeste do Pará) (Souza et al. 1990, modificado a partir de Medeiros et al. 7957, DOCEGEO 1988, Huhn et al. 1988), onde são observados os granitos estudados, Musa e Jamon

Figure 1 - Geological map of Rio Maria region, southeastern of Para State (after Souza et al. 1990, Medeiros et al. 1987, DOCEGEO 1988, Huhn et al. 1988), showing the studied granites Musa and Jamon 
com dados petrográfícos e químicos, as relações entre SM e os processos magmáticos e tardi a pós-magmáticos, e para discutir as condições de fugacidade de oxigênio $\left(\mathrm{fO}_{2}\right)$ presentes em diferentes estágios da evolução magmática desses granitos e suas tipologias.

Pesquisas desse tipo são de extrema importância, haja vista a relação direta entre os minerais ferrimagnéticos presentes em uma rocha e as propriedades magnéticas-magnetização remanescente, SM, anisotropia de SM (Haggerty 1979, 1981a, b. Grant 1985).

Estudos específicos de SM têm auxiliado a definição do potencial metalogenético de granitóides e permitido a identificação de áreas propícias à concentração de minérios (Ishihara 1981, Hattori 1987, Magalhães 1991), uma vez que a ação de soluções magmáticas e hidrotermais, em geral transportadoras e concentradoras de elementos metálicos, costuma acarretar mudanças no sistema original, as quais podem, em certos casos, ser detectadas por variações de SM (Rokov \& Solov'yev 1971,Criss \& Champion 1984, Lapointe et al. 1986, Dall'Agnol et al. 1988, Magalhães 1991). Os dados magnéticos podem permitir a caracterização de regiões com diferentes graus de transformação e, indiretamente, a identificação de zonas mineralizadas. Além disso, estudos de SM também podem contribuir para a separação de fácies precocemente diferenciadas daquelas mais tardias, uma vez que, em rochas graníticas, costuma ocorrer o decréscimo do conteúdo de minerais opacos com o avanço da diferenciação magmática (McGrath 1970, Dall'Agnol et al. 1988, Magalhães 1991).

A classificação de rochas graníticas em séries com magnetita e com ilmenita (Ishihara 1977, 1981) baseia-se em valores de $\mathrm{SM}$, conteúdo de magnetita e razões $\mathrm{Fe}_{2} \mathrm{O}_{3} / \mathrm{FeO}$ em rocha total. Estas séries relacionam-se a condições de formação distintas e a diferentes tipos de mineralizações. Também foi demonstrado que os granitos do tipo I e S australianos (White \& Chappell 1977) possuem assembléias de minerais opacos bem específicas (Whalen \& Chappell 1988), refletindo as condições distintas de $\mathrm{fO}_{2}$ presentes durante a formação de cada tipo. Anderson (1983) e Anderson \& Bender (1989) demonstraram a importância da caracterização dos minerais opacos nos granitos anorogênicos do Proterozóico Médio da América do Norte e a existência de variações expressivas nas condições de $\mathrm{fO}_{2} \mathrm{em}$ queos mesmos se formaram. Isto acentua o interesse na obet al. et al. atenção e discussão dos dados mencionados acima em estudos petrológicos e metalogenéticos.

Este tipo de estudo também se mostrou importante na definição da auréola de contato decorrente do efeito térmico provocado por intrusões graníticas em um metagranitóide (Magalhães \& Dall'Agnol. 1991).

Os inúmeros estudos de petrologia experimental, que utilizam o par mineral magnetita-ilmenita para determinar as condições de $\mathrm{fO}_{2}$ e temperatura $(\mathrm{T})$ em rochas ígneas (Buddington \& Lindsley 1964, Lindsley 1981, Price 1981, Spencer \& Lindsley 1981), também demonstram a importância de estudos nessa área.

\section{ASPECTOS PETROGRÁFícos Granito Musa}

Neste maciço predominam rochas com texturas equigranulares médias, seriadas (médias a finas) e finas. Localmente, há variedades porfiríticas, geralmente com matriz fina e fenocristais médios ou grossos. Os constituintes essenciais - quartzo, plagioclásio e microclínio - são geralmente mais desenvolvidos. Os máficos formam agregados onde se concentram biotita \pm hornblenda e os acessórios primários - apatita, zircão, opacos, titanita \pm allanita.

Dois grupos faciológicos foram distingüidos nesse maciço, monzogranitos e sienogranitos, os quais foram subdivididos em várias subfácies - biotita-anfibólio monzogranito (B AM), anfibólio-biotita monzogranito (ABM), biotita monzogranito (BM - anfibólio < 1\%), leucomonzogranito (LM), anfibólio-biotita sienogranito heterogranular (ABSH), grosso
(ABSG), leucossienogranito (LS) e microssienogranito (MCS) (Gastal 1987). Além dessas subfácies, foram identificadas amostras de biotita sienogranito (BS) equigranulares e heterogranulares, e ABS equigranulares e porfiríticos.

Os principais aspectos petrográfícos referem-se a ambas as fácies, pois elas apresentam grandes similaridades em termos dos seus principais constituintes. No entanto, quando existirem, as diferenças serão assinaladas.

Plagioclásio Apresenta-se essencialmente como dois tipos distintos em morfologia e composição (P11 e P12) (Gastal 1987). Os cristais de P11 possuem dimensão de 1,0 a 5,0 mm e composição na faixa de andesina-oligoclásio cálcico (An35-30 a An28-25) no centro e oligoclásio sódico (An 18-12) nas bordas. Seus cristais são zonados e contêm inclusões de anfibólio e acessórios, inclusive magnetita e ilmenita. Ocorrem comumente transformados em sericita, epídoto, argilominerais e, por vezes, fluorita. Este tipo de plagioclásio é comum nos BAM, ABM e ABS. O P12 constitui cristais de dimensões variáveis entre 0,2 e $1,5 \mathrm{~mm}$, que ocupam os interstícios e situam-se na faixa composicional de oligoclásio sódico (An1815) a albita (An 10). Ocasionalmente, podem apresentar núcleos mais cálcicos (An24-20). Seus cristais apresentam geminação polissintética nítida e estão transformados apenas em sericita. Como inclusões, foram observados quartzo e biotita. Estes cristais são freqüentes nos BM, LM e sienogranitos e raros a inexistentes nos BAM.

Feldspato alcalino Ocorre como microclínio, que, de acordo com Gastal (1987), pode ser subdividido em Mc1 e Mc2. Nos cristais de Mc1, a geminação carlsbad é a mais freqüente, enquanto a geminação albita-periclina é visível em poucas secções. Pertitas do tipo filme são comumente observadas. Apresentam inclusões de quartzo (Qz2, em sua borda), biotita e, mais raramente, titanita e opacos. Os cristais de Mc2 freqüentemente apresentam a geminação albita-periclina visível e pertitas tipo filete. Podem formar intercrescimentos granofíricos com o quartzo. Nas fácies mais evoluídas Mc2, predomina sobre Mc1.

Quartzo Gastal (1987) definiu quatro tipos. Qzl é o mais abundante e possui as maiores dimensões (l a $4 \mathrm{~mm}$ ); Qz2 são finos cristais intersticiais ou inclusos nos feldspatos; Qz3 forma texturas mirmequíticas; Qz4 ocorre como inclusões em minerais ferromagnesianos, em geral, nas porções mais transformadas, sugerindo ser um dos produtos das reações entre os minerais ferromagnesianos. Este tipo de quartzo é mais comum nos ABM e BM. Nos MCS, não foram observados Qz3 e Qz4.

Anfibólio Encontra-se, geralmente, associado ao P11 ou, quando mais transformado, junto a agregados de biotita, titanita, Qz4 e opacos. Opacos, apatita e zircão costumam apresentar-se associados ou inclusos no anfibólio, que desenvolve contatos com P11 e mais raramente com Qz1 (Gastal 1987). A composição deve corresponder a ferro-edenita ou hornblenda ferro-edenítica (Gastal 1987), como demonstram as analogias ópticas com os anfibólios do Granito Jamon analisados por Dall'Agnol (1982).

Biotita Três formas distintas de biotita foram observadas: a. cristais milimétricos que possuem contatos regulares com anfibólio; b. substituindo anfibólio; c. em pequenos cristais intersticiais. Estes tipos de cristais de biotita sugerem estágios diferentes de formação. Em um primeiro estágio, seriam formados, exclusivamente a partir dos elementos disponíveis no magma, os cristais de biotita mais desenvolvidos (Bt1); os cristais de substituição e intersticiais (Bt2) seriam formados mais tardiamente, tanto a partir dos elementos disponíveis no magma, como com elementos provenientes da desestabilização parcial do anfibólio. Nas fácies hololeucocráticas (LM, LS, MCS), a 
biotita apresenta-se comumente em cristais intersticiais e, em algumas fácies, como nos MCS, seu conteúdo é baixíssimo.

Titanita Três formas de ocorrência são comuns: 1. cristais milimétricos e submilimétricos isolados ou associados aos agregados de máficos e opacos; 2 . bordas em torno de ilmenita e magnetita; 3. cristais submilimétricos inclusos em minerais ferromagnesianos.

Titanita do tipo 2 (Tit2) tem sido relacionada a processos de oxidação de ilmenita (Barrirè \& Gotten 1979, Haggerty 1981b) e magnetita com Ti (Haggerty 1981b) durante eventos tardi a pós-magmáticos. No caso do Granito Musa, é possível que estas bordas de titanita possam ter sido geradas ainda num estágio magmático, haja vista as formas subédricas e relações texturais da Tit, sugerindo formação direta a partir do líquido magmático. Apenas Tit3 deve ter sido formado durante o estágio tardi a pós-magmático, uma vez que seu modo de ocorrência sugere ligação com as transformações que ocorreram nos minerais ferromagnesianos. Wones (1989) enfatizou a importância de titanita magmática, associada a magnetita e quartzo, na caracterização de condições relativamente oxidantes durante a evolução magmática. Whalen \& Chappell (1988), com base em Czamanske \& Wones (1973), também sugerem tais condições para granitos do tipo I do cinturão dobrado de Lachlan no sudeste da Austrália.

Minerais acessórios Titanita, allanita, apatita, zircão e opacos representam a assembléia de minerais acessórios dessas rochas. Os minerais opacos serão discutidos a seguir.

Minerais secundários Relacionados às transformações de feldspatos, ocorrem sericita, epídoto, fluorita e argilominerais. Como produto principal de transformação da biotita, observa-se clorita, que é mais abundante nas fácies mais evoluídas.

Granito Jamon Neste maciço são observadas apenas variedades monzograníticas, que correspondem àquelas descritas no Granito Musa (B AM, ABM, BM e LM). Seus aspectos texturais e petrográfícos também são semelhantes. Maiores detalhes podem ser obtidos em Dall'Agnol (1982).

MINERAIS OPACOS Os minerais opacos foram estudados em luz refletida (LR) no microscópio óptico, e a partir da técnica de elétrons retro-espalhados (back scattered elétrons BSE) no microscópio eletrônico de varredura (MEV). Associam-se, principalmente, a agregados de minerais máficos e são, na essência, magnetita, ilmenita e hematita às vezes, ocorrem goethita e pirita. Por causa das semelhanças existentes entre os Granitos Musa e Jamon e, especificamente, entre os tipos e aspectos texturais dos seus minerais opacos, as descrições apresentadas são inerentes aos dois maciços. Discussão sobre as texturas e as composições dos óxidos de Fe e Ti do Granito Jamon é apresentada por Dall'Agnol et al. (inédito).

Magnetita A magnetita com Ti original (TMt) atualmente apresenta-se como magnetita (Mt) pobre em $\mathrm{Ti}$, intercrescida com ilmenita tipo trellis (Ilm T) (Fotos 1 e 2). Em geral, tais intercrescimentos ocorrem em cristais hipidiomórficos e idiomórficos associados aos minerais ferromagnesianos e mostram contatos regulares com estes e íntima relação com outros minerais de óxidos (Ilm e Ht). Por vezes, distribuem-se de forma aleatória, inclusos em minerais félsicos.

Esse tipo de intercrescimento caracteriza o processo de exsolução-oxidação da TMt (Buddington \& Lindsley 1964, Haggerty 1981a) e pode ser explicado pela reação apresentada em Buddington \& Lindsley (1964):

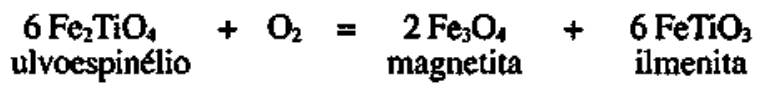

De acordo com Lindsley (1981) e Spencer \& Lindsley (1981), a formação de Ilm T ocorre a temperaturas (T) inferiores a $620^{\circ} \mathrm{C}$, caracterizando uma reação no estágio subsolidus. As lamelas de Ilm T são mais desenvolvidas e mais abundantes na fácies monzogranítica, enquanto nos sienogranitos elas costumam ser muito finas, sendo observadas claramente, apenas, com os maiores aumentos do microscópio óptico ou com a ajuda do MEV. Cristais homogêneos de Mt também ocorrem, entretanto, são menos comuns.

Os cristais de Mt ocorrem sempre parcialmente hematitizados, sendo a intensidade da hematitização variável. A hematita tanto se desenvolve mais intensamente a partir das bordas da Mt como se distribui de forma mais ou menos regular em todo o cristal.

Observa-se, ainda, Mt bordejada por titanita, os contatos entre ambas podem ser regulares ou levemente reentrantes, sugerindo, no último caso, a existência de uma certa interação entre esses minerais.

Ilmenita Os cristais de ilmenita apresentam formas euédricas, subédricas e anédricas. De acordo com os tipos texturais definidos por Buddington \& Lindsley (1964) e Haggerty (1981a), foram observadas:

1. ilmenita tipo trellis (Ilm T), discutida anteriormente (Fotos le 2);

2. ilmenita tipo composite (Ilm C), que representa cristais de Ilm em contato com Mt (Foto 3);

3. cristais individuais (Ilm I), são aqueles que não se acham intercrescidos ou em contato com a Mt. Este tipo de Ilm (fotos 3 e 4) ocorre mais raramente.

Ilm C e Ilm I estão presentes, principalmente, nos monzogranitos, embora também sejam observadas nos sienogranitos. Ambos os tipos podem cristalizar diretamente a partir do magma (Haggerty 1981a). Outras hipóteses têm sido aventadas para explicar a origem de Ilm C, como, por exemplo, a formação a partir da magnetita com Ti, seja através do processo de difusão (Buddington \& Lindsley 1964, Vicent et al. 1954 e Wright 1961 apud Haggerty 1981a) seja por exsolução-oxidação (Buddington \& Lindsley 1964).

São comuns cristais de Ilm invadidos ou bordejados por Tit (Fotos 4 e 5), o que lhes confere bordas irregulares e um caráter xenomórfico. Isso sugere a desestabilização parcial da Ilm I e a utilização de Ti para a formação de titanita. Ca e Si, também necessários para a sua formação, podem ser provenientes da desestabilização de anfibólio ou do próprio líquido magmático.

Hematita $A$ hematita ocorre somente a partir do processo de hematitização da Mt e desenvolve-se, comumente, ao longo dos planos $\{111\}$ desse mineral (cf. fig. 35 de Haggerty 1981b). Segundo o autor citado, o processo de hematitização ocorre sobre cristais de Mt deficientes em Ti. As observações de Haggerty (1981b) são concordantes com o observado, uma vez que o desenvolvimento de Ht ocorre ao longo dos planos de contato entre Ilm T e Mt, sugerindo que a Ht é posterior ao processo de exsolução-oxidação que afetou a magnetita com Ti primária. Levando-se em consideração as semelhanças entre os granitos Musa e Jamon (Dall'Agnol et al. 1986, Gastal 1987, 1988, Magalhães 1991) a deficiência de Ti na Mt é ratificada, haja vista as análises da Mt associada às lamelas de Ilm T em diversas fácies do Granito Jamon (Dall'Agnol et al. inédito) apresentarem baixo conteúdo de Ti. Considerando a $\mathrm{T}$ de formação de Ilm T (Lindsley 1981, Spencer \& Lindsley 1981), admite-se que a martita tenha se formado em $\mathrm{T}$ inferiores a $620^{\circ} \mathrm{C}$, também em condições subsolidus.

Goethita Este mineral ocorre em proporções limitadas e apenas em algumas amostras. Encontra-se associada a Mt e 

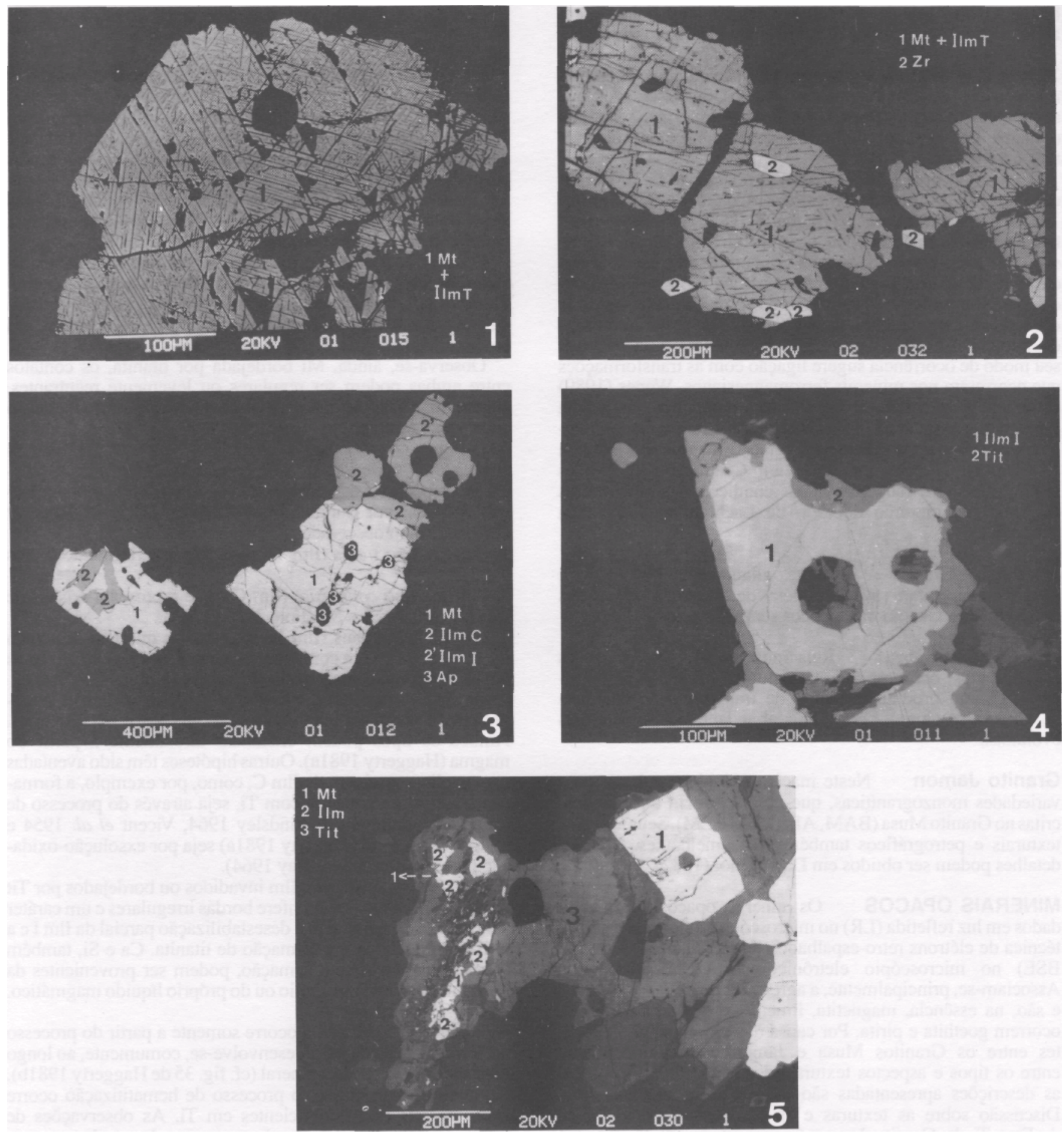

Prancha 1 - Fotomicrografias: Aspectos texturais dos minerais opacos do Granito Musa (microscópio eletrônico de varredura, MEV - elétrons retro-espalhados). 1 e 2 . Cristais de magnetita com Ti primária transformados em intercrescimento de magnetita (Mt, clara) e ilmenita trellis (Ilm T, lamelas escura) por meio do processo de exsolução-oxidação. 1. Amostra KM $77 A$, monzogranito; 2. lamelas de ilmenita são menos abundantes e observam-se cristais automórficos de zircão (Zr, branco) associados ou inclusos no intercrescimento. Amostra KM 6A, sienogranito. 3. Magnetita (Mt) contendo inclusões de apatita (Ap, negra) associada a ilmenita composite (Ilm C). Vê-se, ainda, no alto à direita, um cristal de Ilm I, mostrado em detalhe na foto 4. Amostra KM 77A, monzogranito. 4. Ilmenita I (Ilm I) bordejada por titanita. Amostra KM 77A, monzogranito. 5. Ilmenita (Ilm) desestabilizada por titanita (Tit) e associada a magnetita (Mt), à direita observa-se magnetita automórfica bordejada por titanita. Amostra KM 6A, sienogranito

Plate 1 - Photomicoghraphies: Textural aspects of oxide minerals in the Musa granite (scanning electron microscopy - SEM, back scattered images). Mt $=$ magnetite, $\mathbf{I I m}=$ ilmenite, Tit - titanite, $\mathbf{Z r}=$ zircon, and $\mathbf{A p}=$ apatite. (1), (3) and (4): KM 77A, monzogranite. (2) and (5): KM 6A, syenogranite. 1. Primary titanian magnetite crystal transformed into Mt (light gray) and trellis (T) Ilm (dark gray lamellae) due to oxidation - exsolution. 2. Magnetite-ilmenite intergrowth, similar to that of photo 1, but with more scattered lamellae of Ilm. Automorphic crystals of $\mathrm{Zr}$ (white) are included or associated to the oxide minerals. 3. Mt including Ap (black), and associated to composite (C) Ilm. On the top of the right side, individual (I) Ilm crystal, that is also showed in photo 4.4. Detail of photo 3, showing I Ilm rimmed by Tit Photo. 5. Ilm destabilized by Tit associated to Mt; on the right side, automorphic Mt crystal rimmed by Tit 
substituindo pirita (Pi) nas bordas de seus cristais. A formação de goethita resulta de processos de oxi-hidratação de Mt e Pi. Haggerty (1 981 b) menciona que, em suítes de rochas silicosas, este processo afeta as variedades menos titaníferas de Mt.

Seqüência de formação As evidências texturais indicam que a associação de minerais opacos primária desses granitos é formada por ilmenita (tipos I e C), pirita e magnetita com $\mathrm{Ti}$, atualmente representada pelos intercrescimentos de $\mathrm{Mt}+\mathrm{Ilm} \mathrm{T}$. A associação Mt + Ilm T, bem como hematita e goethita, são fases secundárias. Os estudos composicionais efetuados nesses minerais do Granito Jamon (Dall'Agnol et al. inédito) ratificam as conclusões supracitadas.

Pode-se propor a seguinte seqüência de formação dos minerais opacos:

1. Cristalização de magnetita com Ti, ilmenita (Ilm I e Ilm C) e pirita;

2. substituição parcial de Ilm I por titanita;

3. processo de exsolução-oxidação da magnetita com Ti, gerando intercrescimentos de Mt pobre em Ti com Ilm do tipo trellis (Ilm T);

4. hematitização parcial da Mt;

5. processo de oxi-hidratação com formação de goethita.

A pressão total $(\mathrm{P})$ e a temperatura $(\mathrm{T})$ decrescem de 1 para 5 , enquanto a $\mathrm{fO}_{2}$ apresenta um aumento relativo, considerando as diferentes curvas tampões. Dessa forma, a magnetita com Ti original, com a diminuição da $\mathrm{T}$, seria afetada pelo processo de exsolução-oxidação, gerando intercrescimentos de Mt com Ilm T. A partir daí, haveria um aumento relativo da $\mathrm{fO}_{2}$, conduzindo ao processo de hematitização.

A figura 2 apresenta a ordem de cristalização dos minerais félsicos, ferromagnesianos e opacos da fácies BAM do Granito Musa.

SUSCETIBILIDADE MAGNÉTICA (SM) Aspectos metodológicos Um total de oitenta e quatro (84) amostras do Granito Musa e vinte e oito (28) do Granito Jamon foram submetidas a medidas de SM, obtidas a partir de um equi-pamento de fabricação da Scintrex, modelo CTU-2, o qual permite medir materiais com SM entre $10 \times 10^{-6}$ e $40000 \times 10^{-6}$ cgs-emu $\left(1,257 \times 10^{-4}\right.$ e $5,027 \times 10^{-1}$ SI-emu).

O suscetibilímetro CTU-2 foi calibrado a partir de dois padrões cedidos pelo Instituto Astronômico e Geofísico (IAG) da USP, os quais apresentam SM de $138 \times 10^{-6}$ e $2037 \times 10^{-6}$ cgs-emu.

De acordo com as normas internacionais, as medidas são apresentadas no sistema internacional (SI). Os valores numéricos de SM no SI são $4 \pi(12,566371)$ vezes maiores que no sistema cgs (Hood et al. 1979, Carmichael 1986). Todos os dados apresentados encontram-se em unidade volumétrica $\left(\mathrm{emu} / \mathrm{cm}^{3}\right.$, e para a sua conversão em unidade de massa (emu/g) efetua-se a divisão pela densidade do material medido.

As medidas foram elaboradas em superfícies planas das amostras, as quais foram previamente serradas, a fim de assegurar um bom contato com o sensor. Em cada amostra foram efetuadas várias medidas, e a média delas foi considerada representativa da sua SM.

As amostras ou porções com alteração intempérica visível foram evitadas, por outro lado, as amostras afetadas por transformações tardi a pós-magmáticas foram medidas, a fim de testar a evolução dos opacos e de SM nesses estágios.

A utilização dos dados de SM em diagramas requer escala logarítmica, uma vez que, a partir dos dados logaritmados, há uma melhor estabilização da variância (Larsson 1977). Os dados absolutos de SM comumente apresentam um máximo de freqüência nos intervalos de valores mais baixos, caracterizando uma distribuição lognormal típica (Tarling 1971). No caso específico dos granitos estudados, observa-se um compor-

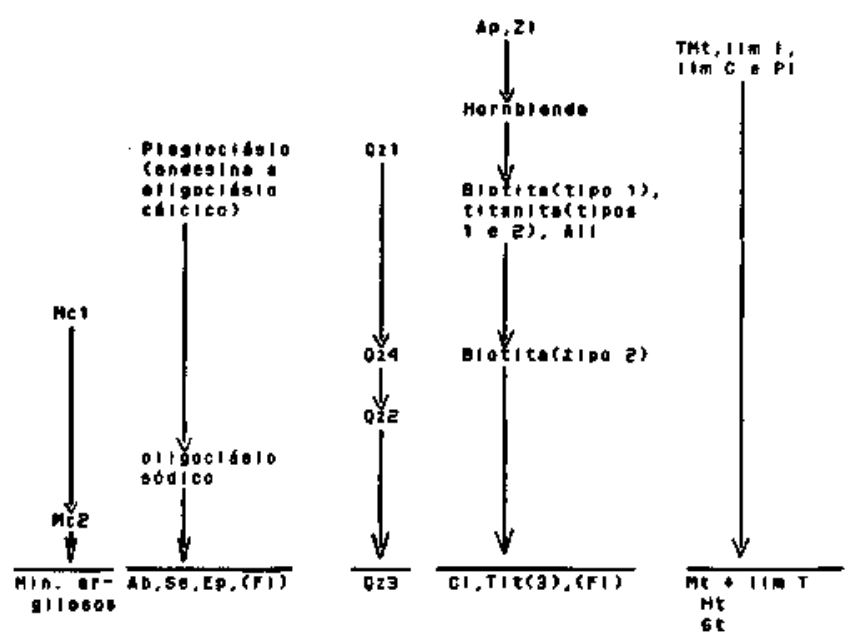

Figura 2 - Ordem de cristalização da fácies biotita-anfibólio monzogranito (BAM) do Granito Musa (Gastal 1987, parcialmente modificada neste trabalho). A linha horizontal marca o início do estágio subsolidus

Figure 2 - Crystallization order in biotite-amphibole monzogranite facies (BAM) of Musa Granite (Gastal 1987, modified). The horizontal line marks the beginning of subsolidus stage

lamento um tanto distinto. Mesmo assim, adotou-se a escala logarítmica, pois a distribuição do tipo lognormal obedece a relação entre SM e conteúdo modal de magnetita apresentada por Mooney \& Bleifuss (1953), não obstante, é a que mais se aproxima da distribuição dos dados de SM desses granitos.

Apresentação dos dados Granito Musa Apresenta SM média de $132,95 \times 10^{-4}$ SI-emu, com valores que variam de $12.57 \times 10^{-4}$ a $321,57 \times 10^{-4}$ SI-emu (Tab. 1) A análise dos dados, utilizando histograma de freqüência e gráfico de probabilidade (Fig. 3), permitiu a separação de três populações de SM, que compreendem diretamente os valores medidos.

Nas tabelas 1 e 2 estão assinaladas estas populações, nas quais se observa a dominância das fácies hololeucocráticas (LM, LS e MCS) na população "A". As rochas que marcam a transição entre fácies menos evoluídas em termos da diferenciação magmática (população "C") e as fácies cristalizadas mais tardiamente (população "A") correspondem à população "B". Nesta, próximo ao limite com a população "A", também ocorrem amostras das fácies hololeucocráticas. Os BAM, ABM e ABSE representam as rochas da população "C".

Granito Jamon Sua SM média é de $130,7 \times 10^{-4}$ SI-emu e seus valores variam de $22,56 \times 10^{-4}$ a $232,21 \times 10^{-4}$ SI-emu. Para este maciço, também foram separadas três populações magnéticas (Fig. 4 e Tab. 3), que apresentam uma excelente correspondência com aquelas do Granito Musa (Tab. 2). Ficam reafirmadas, a partir dos dados de SM, as similaridades desses dois granitos, as quais já haviam sido discutidas, textural e petrograficamente, por outros autores.

Relações entre SM e fácies Observou-se uma excelente correlação entre os dados de SM e a evolução magmática dos granitos Musa e Jamon. Os maiores valores de SM relacionam-se às fácies menos evoluídas segundo o processo de diferenciação magmática, enquanto as fácies cristalizadas tardiamente apresentam SM mais baixa.

Granito Musa O comportamento magnético para cada fácies desse maciço pode ser resumido da seguinte forma: 1. os BAM apresentam SM na faixa de $214,01 \times 10^{-4}$ a 287,39x10 $0^{-4}$ SI-emu (população "C"); 
Tabela 1 - Dados de suscetibilidade magnética (K) do Granito Musa Table l - Magnetic susceptibility (K) data of Musa Granite

\begin{tabular}{|c|c|c|c|c|}
\hline & Amositas & Fácies & $\mathrm{k}\left(\mathrm{emu} / \mathrm{cm}^{3}\right)$ & $\sigma n-1$ \\
\hline \multirow{15}{*}{$\begin{array}{l}\mathrm{P} \\
\mathbf{O} \\
\mathbf{P} \\
\mathbf{U} \\
\mathbf{L} \\
\mathrm{A} \\
\mathbf{C} \\
\mathbf{A} \\
\mathbf{O}\end{array}$} & KM 8 & ABSE & 0,032157 & 0,007809 \\
\hline & CREM 137 & BAM & 0,028739 & 0,001819 \\
\hline & $\mathrm{KM} 61 \mathrm{~A}$ & BAM & 0,028325 & 0,006346 \\
\hline & CREM 139B & $\mathbf{B M}$ & 0,027018 & 0,005380 \\
\hline & KM 87A & BAM & 0,025573 & 0,006635 \\
\hline & CREM 35A & ABM & 0,024856 & 0,003088 \\
\hline & KM 69 & BAM & 0,024127 & 0,002522 \\
\hline & KM 36 & ABSE & 0,023135 & 0,007446 \\
\hline & KM 24 & ABSE & 0,022632 & 0,007373 \\
\hline & $\mathrm{KM} 46$ & ABM & 0,01652 & 0,002959 \\
\hline & CREM 22 & ABSE & 0,01589 & 0,004343 \\
\hline & KM 144B & ABM & 0,021589 & 0,001206 \\
\hline & $\mathrm{KM} \mathrm{73B}$ & BAM & 0,021401 & 0,002485 \\
\hline & CREM 29A & $\mathrm{BM}$ & 0,021275 & 0,002268 \\
\hline & KM 50 & $\mathrm{ABM}$ & 0,021250 & 0,004632 \\
\hline \multirow{10}{*}{ C } & $\mathrm{KM} 71 \mathrm{~A}$ & $\mathbf{B M}$ & 0,020496 & 0,004390 \\
\hline & KM 21 & BAMJ & 0,020408 & 0,004632 \\
\hline & CREM 27 & ABSH & 0,020320 & 0,003492 \\
\hline & $\mathrm{KM} 148$ & $\mathbf{B M}$ & 0,019214 & 0,003323 \\
\hline & KM 77A & $\mathrm{ABM}$ & 0,018887 & 0,001062 \\
\hline & CREM 42A & ABM & 0,018699 & 0,002123 \\
\hline & KM 104 & ABMJ & 0,018510 & 0,001954 \\
\hline & CREM 58A & ABM & 0,018334 & 0,00480 \\
\hline & CREM 62A & ABSH & 0,018309 & 0,008276 \\
\hline & KM 14 & BSE & 0,017945 & 0,005748 \\
\hline \multirow{12}{*}{$\begin{array}{l}\mathbf{P} \\
\mathbf{O} \\
\mathbf{P} \\
\mathbf{U} \\
\mathbf{L} \\
\mathbf{A} \\
\mathbf{C} \\
\mathbf{A} \\
\mathbf{0}\end{array}$} & $\mathrm{KM} 13 \mathrm{~A}$ & ABSH & 0,017731 & 0,004996 \\
\hline & CREM 57A & ABSP & 0,017681 & 0,001472 \\
\hline & KM 6A & ABSH & 0,017417 & 0,004488 \\
\hline & CREM 26B & $\mathrm{ABM}$ & 0,017291 & 0,003711 \\
\hline & KM 112 & $\mathrm{ABM}$ & 0,017241 & 0,003978 \\
\hline & KM 43 & $\mathbf{B M}$ & 0,016801 & 0,002838 \\
\hline & CREM 29C & ABSE & 0,016236 & 0,003330 \\
\hline & KM 88 & BSH & 0,016123 & 0,006756 \\
\hline & $\mathrm{KM} 44 \mathrm{~A}$ & LSH & 0,015783 & 0,001261 \\
\hline & CREM 59B & BSE & 0,015080 & 0,004126 \\
\hline & CREM 102A & $\mathrm{ABM}$ & 0,014740 & 0,002522 \\
\hline & CREM 40 & $\mathbf{B M}$ & 0,014162 & 0,003274 \\
\hline \multirow{7}{*}{$B$} & KM 82 & LMSE & 0.013722 & 0,002244 \\
\hline & CREM 25 & $\mathbf{B M}$ & 0,013170 & 0,004705 \\
\hline & CREM $60 \mathrm{~B}$ & ABSE & 0,013006 & 0,003161 \\
\hline & KM 30A & $\mathbf{B M}$ & 0,012642 & 0,002498 \\
\hline & CREM 141E & ABSH & 0,012428 & 0,002268 \\
\hline & KM 133 & $\mathbf{B M}$ & 0,012353 & 0,000869 \\
\hline & KM 37 & ABSH & 0,011699 & 0,000458 \\
\hline
\end{tabular}

Continua

2. os ABM apresentam SM principalmente entre $147,40 \times 10^{-4}$ e $248,56 \times 10^{-4}$ SI-emu (população "C" e porção superior da população "B");

3. os BM apresentam distribuição ampla, ocorrendo em todas as populações de SM, com valores que variam de $49,51 \times 10^{-4}$

\begin{tabular}{|c|c|c|c|c|}
\hline \multirow{13}{*}{$\begin{array}{l}\mathbf{P} \\
\mathbf{O} \\
\mathbf{P} \\
\mathbf{U} \\
\mathbf{L} \\
\mathbf{A} \\
\mathbf{C} \\
\mathbf{A} \\
\mathbf{O}\end{array}$} & Amostras & Fácies & $k\left(\mathrm{emu} / \mathrm{cm}^{3}\right)$ & $\sigma_{n-1}$ \\
\hline & KM 80 & ABSH & 0,011548 & 0,002401 \\
\hline & KM 136 & BSH & 0,011184 & 0,003007 \\
\hline & $\mathbf{K M} 9$ & BM & 0,011033 & 0,001625 \\
\hline & $\mathrm{KM} 153$ & LSH & 0,010568 & 0,000825 \\
\hline & CREM 37A & BM & 0,010518 & 0,002992 \\
\hline & $\mathrm{KM} 45 \mathrm{~A}$ & LSE & 0,009940 & 0,003007 \\
\hline & $\mathrm{KM} 114$ & LMM & 0,009576 & 0,000728 \\
\hline & KM 150 & LSH & 0,009437 & 0,001375 \\
\hline & KM 118 & LMM & 0,009437 & 0,000485 \\
\hline & KM 65 & ABSH & 0,009211 & 0,001592 \\
\hline & $\mathrm{KM} 147$ & $\mathbf{B M}$ & $0,009\rfloor 48$ & 0,000994 \\
\hline & KM 2A & LSE & 0,009098 & 0,002799 \\
\hline \multirow{14}{*}{$\mathbf{B}$} & $\mathrm{KM} 130$ & LMM & 0,008734 & 0,002037 \\
\hline & $\mathrm{KM} \mathrm{42B}$ & LMM & 0,008558 & 0,000655 \\
\hline & KM 10 & LSP & 0,008168 & 0,000970 \\
\hline & KM 115 & BM & 0,007867 & 0,002702 \\
\hline & CREM 41A & ABSH & 0,007791 & $\mathbf{x}$ \\
\hline & KM 79 & LSH & 0,007515 & 0,001649 \\
\hline & KM 131 & LMM & 0,007150 & 0,000412 \\
\hline & CREM 57B & LMSH & 0,007138 & 0,000265 \\
\hline & KM 29 & $\mathbf{B M}$ & 0,007050 & 0,000844 \\
\hline & KM 116 & LSH & 0,007025 & 0,002533 \\
\hline & KM 26D & ABSG & 0,007025 & 0,001858 \\
\hline & KM 70A & LSH & 0,006912 & 0,001382 \\
\hline & KM 149 & $\mathrm{BM}$ & 0,006886 & 0,001916 \\
\hline & CREM 32 & LM & 0,006245 & 0,003860 \\
\hline \multirow{7}{*}{$\begin{array}{l}\mathbf{P} \\
\stackrel{\mathrm{O}}{\mathrm{P}} \\
\mathbf{U} \\
\mathrm{L} \\
\mathrm{A} \\
\stackrel{\mathrm{C}}{\mathrm{A}} \\
\mathrm{O}\end{array}$} & $\mathrm{KM} 7 \mathrm{~A}$ & LSE & 0,005944 & 0,000970 \\
\hline & KM 45B & LMM & 0,005793 & 0,000461 \\
\hline & KM 67 & $\mathbf{L M}$ & 0,005454 & 0,001067 \\
\hline & KM 84 & LSH & 0,005064 & 0,000700 \\
\hline & KM 129 & $\mathrm{BM}$ & 0,004951 & 0,001810 \\
\hline & CREM 140B & LSE & 0,004612 & 0,001013 \\
\hline & KM 23 & LMSE & 0,003707 & 0,000509 \\
\hline \multirow[t]{7}{*}{ A } & KM 17 & LSH & 0,003644 & 0,000412 \\
\hline & KM 13B & LMSE & 0,002991 & 0,000000 \\
\hline & CREM 62B & LSH & 0,002802 & 0,000651 \\
\hline & CREM 101B & $\mathbf{L M M}$ & 0,002174 & 0,000772 \\
\hline & KM 22 & LSH & 0,001797 & 0,000194 \\
\hline & CREM 101A & $\mathbf{L M}$ & 0,001257 & 0,000386 \\
\hline & KM 154 & LMSE & 0,000075 & 0,000046 \\
\hline
\end{tabular}

Fácies: $A=$ anfibolio; $B=$ biotita; $S=$ sienograrito; $M=$ monzogranito; $E=$ equigranular;

$\mathrm{H}=$ heterogranular; $\mathrm{P}=$ porfíítico: $\mathrm{L}=$ leuco; $\mathrm{LM}=$ leucomicto; $\mathrm{J}=$ Granito Jamon

K: em unidade do Sistema Intemacional (SI). $\sigma$ n-1 (desvio-padrão): $\mathrm{x}=1$ medida. a $270,18 \times 10^{-4}$ SI-emu. Concentram-se, entretanto, na população "B";

4. as variedades portando anfibólio da fácies sienogranítica apresentam igualmente distribuição ampla, situando-se nos vários intervalos de SM, com variação de $70,25 \times 10^{-4} \mathrm{a}$ 

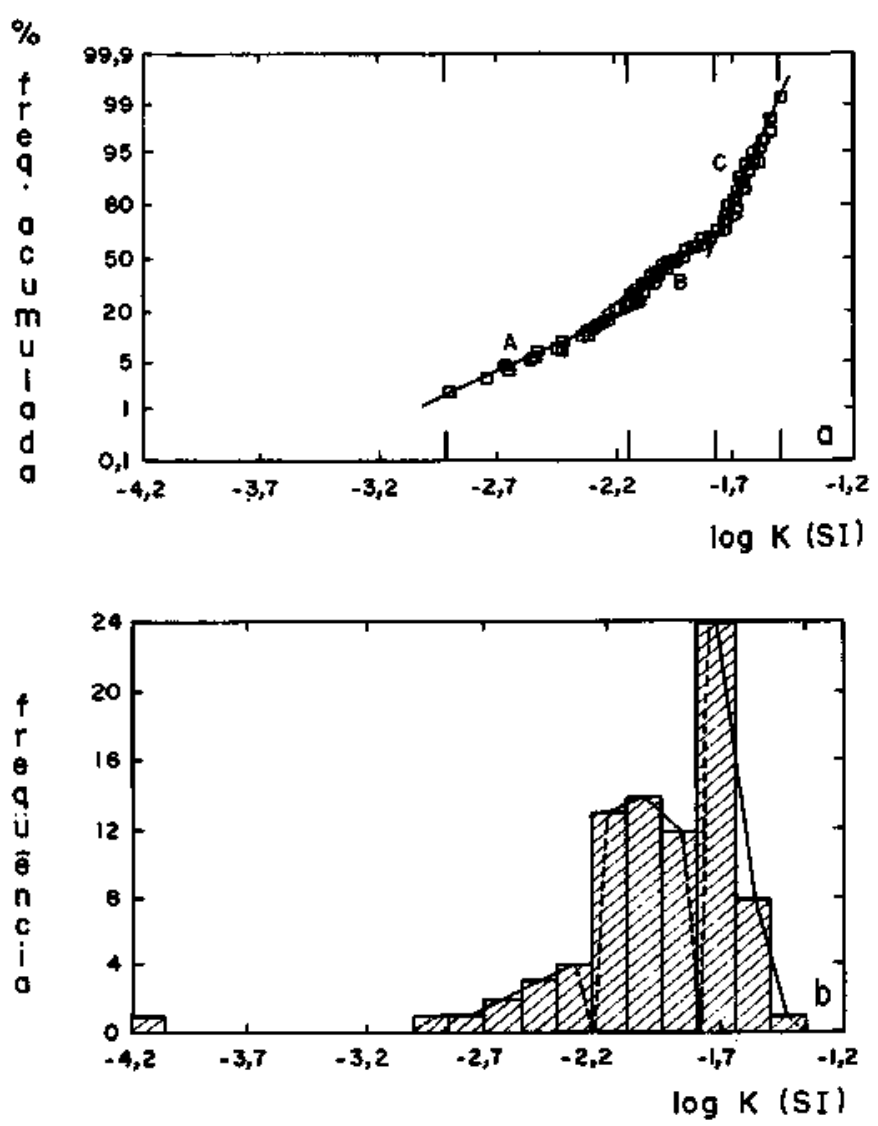

Figura 3 - (a) Diagrama de probabilidade e (b) histograma de freqüencia referentes aos dados de siiscetibilidade magnética (log k) do Granito Musa

Figure 3 - The logs of measurements of magnetic susceptibility (K) for Musa Granite are plotted against (a) their cumulative frequency on a probability scale, and in (b) frequency histogram

$321,57 \times 10^{-4} \mathrm{Si}$-emu. Constatam-se, no entanto, diferenças importantes entre suas diversas subfácies:

- os ABSE concentram-se na população "C";

- os ABSH, ABSG e ABSP possuem valores de SM de $70,25 \times 10^{-4}$ a $203,20 \times 10^{-4}$ SI-emu, predominando os valores correspondentes à população "B";

5. as variedades sienograníticas sem anfibólio (BSE e BSH) são de ocorrência reduzida no maciço e distribuem-se apenas na população "B";

6. as subfácies hololeucocráticas (LM, LS e MCS) apresentam valores de SM concentrados na população "A" $\left(12,57 \times 10^{-4} \mathrm{a}\right.$ $70,67 \times 10^{-4}$ SI-emu) ou na porção inferior da população

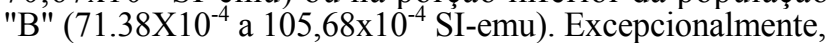
possuem SM mais elevada (amostra KM 44A e KM 82, $\mathrm{SM}=157,83 \times 10^{\prime \prime}$ e $137,22 \times 10^{\prime \prime}{ }^{4}$ SI-emu, respectivamente). Considerando a correlação positiva entre SM e conteúdo modal de magnetita, é difícil explicar o porquê de algumas porções leucossienograníticas possuírem ainda conteúdo apreciável de magnetita, uma vez que as transformações observadas nestas variedades e o próprio processo de diferenciação magmática tenderiam a reduzir o conteúdo de magnetita. De qualquer modo, os valores de SM obtidos mostram que as condições de $\mathrm{fO}_{2}$ permitiram a formação de magnetita nessas rochas em proporções consideráveis, apesar de seus conteúdos de Fe serem inferiores aos das demais fácies. É provável que os valores mais baixos de SM nos leucogranitos reflitam ao mesmo tempo a menor disponibilidade de Fe e os efeitos das transformações dos opacos primários (magnetita para martita).
Tabela 2 - Populações de suscetibilidade magnética $(K)$ e fácies correspondentes dos granitos Musa e Jamon Table 2 - Magnetic susceptibility $(K)$ groups and respective facies of Musa and Jamon granites

\begin{tabular}{|c|c|c|c|c|}
\hline & Populaçōes & $\begin{array}{c}\text { Intervalos de SM } \\
\left(x \quad 10^{4} \text { e mufom do SI) }\right.\end{array}$ & $\begin{array}{l}\text { Proporçbes } \\
\text { aproximadns } \\
\text { dos dados } \\
\text { (\%) }\end{array}$ & Facies* \\
\hline \multirow{2}{*}{$\begin{array}{l}\mathbf{G} \\
\mathbf{R} \\
\mathbf{A} \\
\mathbf{N} \\
\mathbf{I} \\
\mathbf{T} \\
\mathbf{O}\end{array}$} & A & $13 \cdot 71$ & 20 & $\begin{array}{c}\text { Leucogranitos } \\
\text { (LMLS e } \\
\text { MCS) }\end{array}$ \\
\hline & B & $71-178$ & 50 & $\begin{array}{c}\text { ABSH, ABSP, } \\
\text { BM e } \\
\text { leucogratitos }\end{array}$ \\
\hline $\begin{array}{l}\mathbf{M} \\
\mathbf{S} \\
\mathbf{A} \\
\end{array}$ & C & $178=322$ & 30 & $\begin{array}{l}\text { BAM, ABM E } \\
\text { ABSE }\end{array}$ \\
\hline \multirow{2}{*}{$\begin{array}{c}\mathrm{G} \\
\mathrm{R} \\
\mathrm{A} \\
\mathrm{N} \\
\mathrm{I} \\
\mathrm{T} \\
\mathrm{O}\end{array}$} & A & $23-40$ & 15 & Leucogrunitos \\
\hline & B & $40-178$ & 55 & $\begin{array}{c}\text { ABM, BMH e } \\
\text { alguns } \\
\text { leucogranitos }\end{array}$ \\
\hline $\begin{array}{l}\mathbf{J} \\
\mathrm{A} \\
\mathbf{M} \\
\mathbf{O} \\
\mathrm{N}\end{array}$ & C & $178-232$ & 30 & $\begin{array}{l}\text { BAME e } \\
\text { ABME }\end{array}$ \\
\hline \multicolumn{5}{|c|}{$\begin{array}{l}\text { * Foram consideradas as fácies mais representativas de cada população, as } \\
\text { variações podem ser observadas nas tabelas de dados. }\end{array}$} \\
\hline \multicolumn{2}{|c|}{$\begin{array}{l}\text { A: anfibólio } \\
\text { B:biotita } \\
\text { L: leuco }\end{array}$} & $\begin{array}{l}\text { MC: micro } \\
\text { M: monzogranito } \\
\text { S: sienogranito }\end{array}$ & $\begin{array}{l}\text { equigranular } \\
\text { grosso } \\
\text { heterogranular }\end{array}$ & P: porfirítico \\
\hline
\end{tabular}

De acordo com a distribuição dos valores de SM em mapa (Fig. 5) observa-se que as diversas populações ocorrem entremeadas e não concentradas em determinadas porções do maciço. Isso é decorrência do posicionamento aleatório das fácies monzograníticas e sienograníticas, bem como de suas variedades mais leucocráticas.

Granito Jamon Para cada fácies, observou-se o seguinte comportamento magnético:

1. apenas uma amostra de BAM foi medida e possui SM dentro do intervalo da população "C";

2. os ABM apresentam SM predominantemente entre $189,87 \times 10^{-4}$ e $232,21 \times 10^{-4}$ SI-emu (população "C"), apenas duas amostras têm SM mais baixa (população "B");

3. os BM distribuem-se essencialmente na população "B", apenas uma amostra (AU-386), com o maior conteúdo de biotita registrado para este granito, ocorre na população "C"; 4. os LM (máficos $<5 \%$ ) apresentam SM variável entre $22,56 \times 10^{-4}$ e $153,81 \times 10^{-4}$ SI-emu, sendo possível distinguir dois grupos:

- LM com anfibólio têm SM entre $115,06 \times 10^{-4}$ e $153,81 x$ $10^{-4}$ SI-emu (população "B");

- LM sem anfibólio possuem SM entre $22,56 \times 10^{-4}$ e $77,37 \times 10^{-4}$ SI-emu (porção inferior da população "B" e toda a população "A").

Conforme discutido para o Granito Musa, a população "B" marca a transição entre rochas formadas precocemente e aquelas cristalizadas mais tardiamente. Outro aspecto importante é a predominância de rochas com textura equigranular com os maiores valores de SM (população "C" e porção superior da população "B"); enquanto as rochas com textura heterogranular ocorrem na porção inferior da população "B". Isto pode 


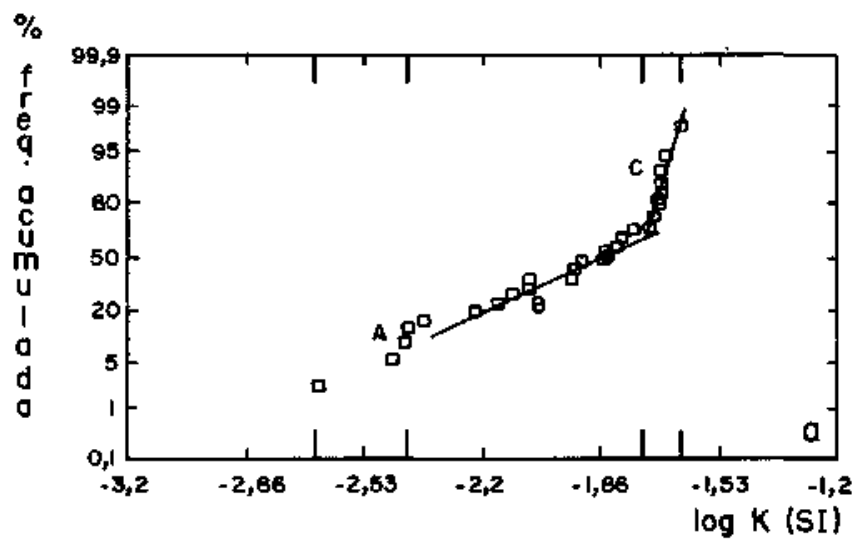

Tabela 3 - Dados de suscetibilidade magnética (K) do Granito Jamon

Table 3 - Magnetic susceptibility (K) data of Jamon Granite

\begin{tabular}{|c|c|c|c|c|}
\hline & Amostras & Fácies & $\mathrm{K}\left(\mathrm{emu} / \mathrm{cm}^{3}\right)$ & $\sigma n-1$ \\
\hline 5 & AU 392 & ABME & 0,02322140 & 0,00233773 \\
\hline $\mathbf{P}$ & AU 393 & ABME & 0,02093683 & 0,00528893 \\
\hline $\mathrm{U}$ & AU 383 & BAME & 0,02051586 & 0,00398831 \\
\hline L & AU 391 & ABME & 0,02030223 & 0,00202105 \\
\hline$\stackrel{A}{C}$ & AU 387 & GE & 0,02009237 & 0,00427206 \\
\hline $\mathrm{A}$ & AU 386 & BME & 0,01998556 & 0,00098897 \\
\hline 0 & AU 389 & ABME & 0,01984230 & 0,00108096 \\
\hline C & AU 385 & ABME & 0,01941504 & 0,00213653 \\
\hline & AU 380 & ABME & 0,01898653 & 0,00187440 \\
\hline & AU 400 & ABME & 0,01691685 & 0,00030285 \\
\hline & AU 381 & BME & 0,01598819 & 0,00315353 \\
\hline & AU 372 & LME & 0,01538124 & 0,00420320 \\
\hline $\mathbf{P}$ & AU 374 & ABME & 0,01456065 & 0,00422519 \\
\hline 0 & AU 384 & LME & 0,01418995 & 0,00175301 \\
\hline$P$ & AU 370 & BME & 0,01391851 & 0,00214131 \\
\hline $\mathbf{U}$ & AU 378 & BMH & 0,01218184 & 0,00071855 \\
\hline $\bar{A}$ & AU 373 & BMH & 0,01175333 & 0,00035927 \\
\hline$\stackrel{C}{A}$ & AU 394 & LME & 0,01150577 & 0,00295259 \\
\hline $\begin{array}{l}A \\
O\end{array}$ & AU 375 & BMH & 0,00870850 & 0,00126883 \\
\hline & AU 382 & BMH & 0,00863687 & 0,00010091 \\
\hline B & AU 395 & LMM & 0,00773711 & 0,00183482 \\
\hline & AU 396 & LMM & 0,00708115 & 0,00099727 \\
\hline & AU 371 & BMH & 0,00613867 & $x$ \\
\hline & AU 377 & BMH & 0,00435425 & 0,00030285 \\
\hline$\overline{\mathbf{P}}$ & AU 376 & GAL & 0,00392573 & 0,00070661 \\
\hline 0 & AU 398 & LMM & 0,00388301 & 0,00077145 \\
\hline . & AU 399 & $\mathbf{L M M}$ & 0,00356885 & 0,00121127 \\
\hline A & AU 397 & MG & 0,00225566 & 0,00251026 \\
\hline
\end{tabular}

sugerir que rochas equigranulares possuam valores mais elevados de $\mathrm{SM}$, devido à uniformidade no tamanho de seus cristais, uma vez que a SM pode variar em função da forma e tamanho dos cristais de magnetita principalmente. No entanto, o mais provável é que as feições texturais estejam relacionadas a evolução magmática do maciço. Dessa forma, as variações dos valores de SM e conteúdo de magnetita estão marcando tanto o processo de diferenciação magmática (BAM+ABM - > BM - > LM) como as diferenças texturais, sendo que estas últimas estão diretamente relacionadas ao processo de diferenciação.

Relações entre SM e conteúdo mineral O conteúdo de opacos nestes granitos é expressivo (Tab. 4). A grande maioria de suas amostras apresenta valores mensuráveis a partir de análise modal. A correlação entre SM e opacos é positiva (Fig. 6) e, agrupando as amostras de cada fácies, percebese que as mesmas seguem o trend de diferenciação magmática, ou seja, observa-se uma tendência geral de diminuição de SM e opacos no sentido BAM - > ABM $->$ ABS $->$ BM+(LM+LS) para o Granito Musa e BAM+ABM - > BM - > LM para o Granito Jamon. A sobreposição parcial entre as fácies é justificável, haja vista as suas afinidades petrológicas e as próprias imprecisões nas medidas de SM e/ou conteúdos de opacos. Além disso, a presença de quantidades variáveis de outros minerais opacos, como por exemplo ilmenita e pirita, deve proporcionar a obtenção de valores de SM diferentes em amostras com conteúdos de opacos semelhantes, uma vez que os conteúdos de magnetita, mineral ao qual a SM está diretamente relacionada, devem variar. Outro ponto a destacar é a heterogeneidade da distribuição, for-

Fácies: $\mathrm{A}=$ anfíbólito, $\mathrm{B}=$ biotita; $\mathrm{M}=$ monzogranito;

$\mathrm{G}=$ granito; $\mathrm{H}=$ heterogranular; $\mathrm{AL}=$ alasquítico;

$\mathrm{E}=$ equigranular; $\mathrm{LM}=$ leucomicro

$\mathrm{K}$ : em unidade do Sistema Internacional (SI).

on-1 (desvio-padrão): $\mathrm{x}=1$ medida.

ma e tamanho dos cristais de magnetita, o que deve acarretar variações de SM em amostras com mesmas quantidades de magnetita.

No Granito Jamon, especificamente, observam-se dois tipos de comportamento para os BM: amostras que definem uma correlação positiva clara e amostras cuja variação de SM não corresponde a mudanças na quantidade de opacos.

Também os LM desse maciço definem uma correlação distinta das demais fácies. Para amostras com conteúdos mais elevados de opacos, a SM é menor e vice-versa, caracterizando uma correlação negativa. Isto sugere que as amostras com conteúdos elevados de minerais opacos não possuem, certamente, muita magnetita. Isso é coerente com as observações de Dall'Ágnol et al. (inédito). Estes autores mostram que nessa fácies, grande parte da magnetita original foi transformada em hematita ou goethita.

Uma correlação positiva entre SM e conteúdos modais de anfibólio e máficos (Figs. 7a e 7b) também pode ser observada. Este tipo de relação é nítida entre SM e anfibólio (Fig. 7a), ficando clara a coincidência de valores de SM mais elevados com as fácies mais ricas em anfibólio, que são as mais precoces no processo de diferenciação magmática.

A correlação positiva entre SM e máficos (Fig. 7b) reflete a relação direta entre os conteúdos modais de máficos e magnetita nas diferentes fácies. Como no caso do anfibólio, as fácies 


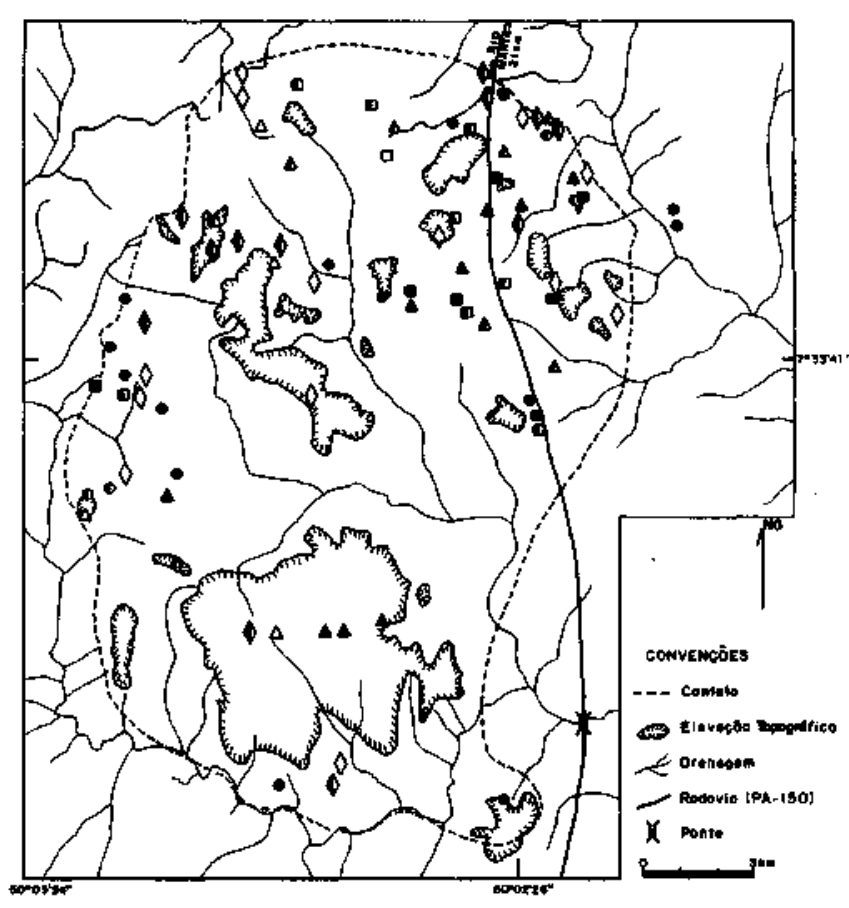

LEGEHOA

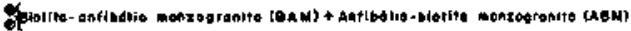

7.

1:*0.

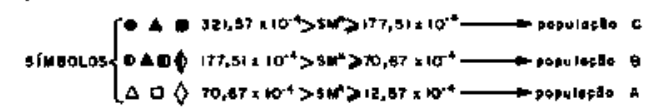

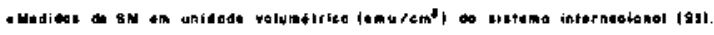

Figura 5 - Mapa integrado de variação de suscetibilidade magnética (SM) e composição mineralógica do Granito Musa. Classificação das fácies baseada em Gastal (1987) e Magalhães (1991)

Figure 5 - Relationship between magnetic susceptibility and petrographic facies of the Musa Granite. The facies were classified by Gastal (1987) and Magalhães (1991)

mais ricas em máficos são, de modo geral, menos evoluídas no processo de diferenciação e possuem SM mais elevada, devido à formação relativamente acentuada de magnetita nos estágios iniciais da cristalização. Isso confirma a tendência geral de diminuição da SM no sentido das rochas mais evoluídas. Além disso, estas são mais afetadas pelos processos tardi a pósmagmáticos e, conseqüentemente, mais ricas em clorita. Daí a correlação negativa entre SM e este mineral (Fig. 7c). Para as fácies BAM e ABM do Granito Jamon, o baixo conteúdo de clorita não permite observar mudanças de SM em função da variação quantitativa desse mineral. Também para os ABS (Granito Musa) não fica claro o tipo de correlação entre essas variáveis, no entanto, a correlação negativa deve ser a mais coerente.

Não parece existir uma correlação direta entre SM e conteúdos modais de biotita nas fácies portadoras de anfibólio de ambos os maciços (BAM, ABM, ABSE, ABSH) e nos leucogranitos do Granito Musa (LM, LS, MCS), ao passo que nos BM dos dois corpos e nos LM do Granito Jamon, os dados disponíveis sugerem uma correlação positiva (Fig. 8). Esse aspecto necessita ser melhor investigado.

Como pôde ser observado, existem algumas diferenças nas relações entre SM e conteúdos minerais dos granitos Musa e Jamon, que podem ser decorrência das causas destacadas anteriormente para as variações dos valores de SM, ou mesmo, conseqüência de pequenas diferenças evolutivas dos dois maciços.

Relações entre SM e conteúdo químico Constatase uma correlação positiva entre os valores de SM e aqueles dos óxidos de $\mathrm{Fe}^{3+}, \mathrm{Fe}^{2+}, \mathrm{Mg}^{2+}$ e $\mathrm{Ti}^{4+}$ (Figs. 9 e 10, dados químicos obtidos em Dall'Agnol (1982) e Gastal (1987) para os granitos Musa e Jamon, respectivamente). As correlações são extremamente bem marcadas no Granito Jamon, ficando claro o trend de evolução magmática (BAM+ABM -> BM -> LM).

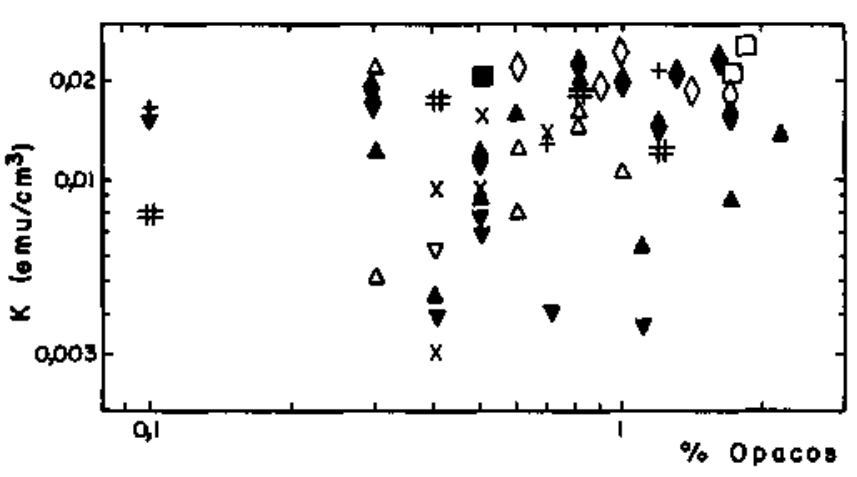

GRANITO MUSA
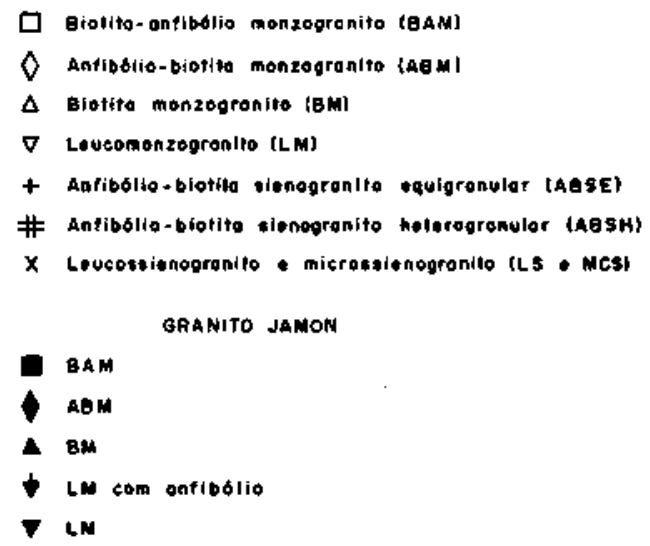

Figura 6 - Diagrama mostrando o comportamento de suscetibilidade magnética $(K)$ versus conteúdo de opacos nas diversas fácies dos Granitos Musa e Jamon

Figure 6 - Magnetic susceptibility (K) versus opaque mineral modal contents plot for Musa and Jamon granites

As rochas mais enriquecidas nos óxidos citados são as mais preco-ces segundo o processo de diferenciação (BAM+ABM) e possuem, por sua vez, SM mais elevada do que as fácies relativamente mais evoluídas (BM e LM). Para o Granito Musa, o número de amostras, que possuem simultaneamente medidas de SM e dados químicos, é reduzido, não permitindo uma discussão mais aprofundada. Mas as similaridades entre este granito e o Maciço Jamon, bem como as interpretações anteriores, reforçam a idéia de que o comportamento entre as variáveis citadas seja semelhante ao observado para o Granito Jamon.

$\mathrm{O}$ diagrama $\mathrm{Fe}_{2} \mathrm{O}_{3} \times \mathrm{FeO}$ do Granito Musa foi discutido por Gastal (1987) (Fig. 11). Essa autora observou que a maioria das fácies apresenta razões em tomo de um $(1,0)$, sendo que os monzogranitos (BAM, ABM, BM e parte dos LM) e os ABS tendem a possuir razões superiores a um $(1,0)$, enquanto os LS apresentam razões próximas a um $(1,0)$ e os MCS razões geralmente menores que um $(1,0)$, próximas a 0,5 .

As razões $\mathrm{Fe}_{2} \mathrm{O}_{3} / \mathrm{FeO}$ (Fig. 11) do Granito Jamon, em geral, estão próximas a um $(1,0)$, algumas amostras possuem razões superiores ou inferiores. Estes valores próximos e superiores a 1,0 revelam que condições oxidantes também foram importantes durante a evolução desse granito. 
Tabela 4 - Composições modais médias das diversas fácies dos Granitos Musa e Jamon

Table 4 - Average modal contents of Musa and Jamon granites

\begin{tabular}{|c|c|c|c|c|c|c|c|c|c|c|c|}
\hline \multirow{2}{*}{ Minerais } & \multicolumn{8}{|c|}{ Granito Musa* } & \multicolumn{3}{|c|}{ Granito Jamon"1 } \\
\hline & $\begin{array}{r}\text { BAM } \\
\text { (3) }\end{array}$ & ABM (9) & BM (6) & LM (S) & ABS (14) & LS (5) & $\operatorname{MCS}(6)$ & $\begin{array}{r}\text { BAM } \\
\text { (2) }\end{array}$ & $\begin{array}{r}\mathrm{ABM} \\
\text { (8) }\end{array}$ & BM (9) & LM (8) \\
\hline Plagioclásio & 30,9 & 34,3 & 28,0 & 26,0 & 17,0 & 18,2 & 18,4 & 25,2 & 32,3 & 28,5 & 29,0 \\
\hline Mieroclínio & 27.6 & 26,9 & 33.4 & 37.5 & 46,7 & 46.6 & 47,4 & 33.2 & 28,2 & 31,3 & 35.7 \\
\hline Quartzo & 31,0 & 29,6 & 31,3 & 33,8 & 30,3 & 33,2 & 32,9 & 35,2 & 30,3 & 32,1 & 32,0 \\
\hline Anfitbálio & 4,0 & 2,0 & 0,25 & - & 0,4 & - & - & 2,4 & 2,0 & 0,2 & 0,1 \\
\hline Biotila & 3,2 & 4.4 & 5,2 & 0.4 & 3,4 & 0,3 & 0,5 & 1,6 & 5,1 & 5,6 & 1,2 \\
\hline Clorita & 0,1 & 0,4 & 0.4 & 1.2 & 0.6 & 1.0 & 0,2 & 0,2 & 0.3 & 0,5 & 0,85 \\
\hline Opacos & 1,7 & 0,9 & 0,6 & 0.5 & 0,8 & 0,4 & 0,4 & 0,6 & 1,0 & 0,9 & 0,5 \\
\hline Titanita & 0,6 & 1,1 & 0,5 & 0,3 & 0,5 & 0,1 & $\mathbf{T r}$ & 1,2 & 0,4 & 0,5 & 0.1 \\
\hline Allanita & 0,1 & Tr & 0,1 & 0.1 & 0,1 & Tr & - & - & - & - & - \\
\hline Fuorita & $\mathrm{Tr}$ & $T r$ & $\operatorname{Tr}$ & 0,1 & $\operatorname{Tr}$ & 0,1 & 0,1 & - & . & - & - \\
\hline Apatita & 0,4 & 0.2 & $\operatorname{Tr}$ & $\operatorname{Tr}$ & 0,1 & 0,1 & - & - & - & - & - \\
\hline Outros & 0,2 & 0,2 & 0,25 & 0,2 & 0,1 & $\mathrm{Tr}$ & 0,2 & 0,4 & 0,5 & 0,5 & 0,3 \\
\hline Felsicos & 89.6 & 90,8 & 92.7 & 97,2 & 94,0 & 98,0 & 98,7 & 93,6 & 90,8 & 91,9 & 96,9 \\
\hline Maficos & 10,4 & 9,2 & 7,3 & 2,8 & 6,0 & 2,0 & 1,3 & 6,4 & 9,2 & 8,1 & 3,1 \\
\hline
\end{tabular}

- Dados obtidos a partir de Gastal (1987)

"1 Dados obtidos a partir de Dall'Agnol (1980)

() Nómero de amostras analisadas

Ver tabela 2 para entender abreviauras das fícies

DISCUSSÃO Os valores de SM relativamente elevados, os conteúdos modais de opacos $>0,1 \%$, a presença constante de magnetita em todas as fácies, bem como as razões $\mathrm{Fe}_{2} \mathrm{O}_{3} / \mathrm{FeO}$ (rocha total) próximas a um $(1,0)$ são características que permitem classificar os maciços Musa e Jamon como granites da série a magnetita de acordo com a definição de Ishihara (1981). Condições de $\mathrm{fO}_{2}$ próximas às do tampão $\mathrm{Ni}-\mathrm{NiO}$ devem ter predominado durante a formação dessas rochas (Whalen \& Chappell 1988, Wones 1989, Dall'Agnol et al inédito). A fO cresceu, em termos relativos, conforme a diferenciação magmática se processava, haja vista a hematitização e a cloritização mais intensas nas fácies mais evoluídas.

É importante salientar que a classificação proposta por Ishihara $(1977,1981)$ não deve ser utilizada com a conotação tectônica discutida por este autor, mas apenas em termos das características supracitadas. $\mathrm{O}$ ambiente tectônico do cinturão orogênico circum-pacífico, onde ocorrem as rochas a partir das quais foi elaborada esta classificação, é certamente muito distinto daquele dos granitos estudados no presente trabalho. Por outro lado, Anderson (1983) e Anderson \& Bender (1989) também empregaram esta classificação para granitos anorogênicos da América do Norte, e Hattori (1987) compara as intrusões félsicas associadas a depósitos de ouro do Arqueano no Canadá à série a magnetita de Ishihara (1977). Os dados aqui apresentados confirmam, portanto, a existência de granitos anorogênicos proterozóicos da série com magnetita, formados em condições de $\mathrm{fO}_{2}$ relativamente elevadas, e reforçam a importância de estudos de minerais opacos e SM.

Ishihara (1981) assinalou que granitos da série a magnetita podem ser correlacionados a granitos do tipo I australianos descritos por Chappell \& White (1974). As paragêneses descritas em Whalen \& Chappell (1988) nos granitos do tipo I da Austrália são coincidentes com aquelas observadas nos granitos Musa e Jamon. Isso poderia sugerir uma correlação entre esses e os granitos do tipo I-caledoniano de Pitcher (1983). Tal correlação já se encontra documentada em Dall'Agnol et al. (1987) e Gastal $(1987,1988)$. Entretanto, novos dados geoquímicos (Dall'Agnol et al. em preparação) mostram que esses maciços possuem características de granitos do tipo A, assemelhando-se mais àqueles proterozóicos metaluminosos do tipo A do sudoeste dos Estados Unidos, que são discutidos em Anderson \& Bender (1989).

Tendo em vista as semelhanças entre os granitos Musa e Jamon (Dall'Agnol et al. 1986,1987 e Gastal 1987,1988) e a presença da assembléia titanita + magnetita + quartzo ficam reafirmadas as condições de $\mathrm{fO}_{2}$ elevadas durante a cristalização dos mesmos, como discutido por Dall'Agnol et al. (inédito) para o Granito Jamon e por Wones (1989) para essa associação mineral.

Quanto às temperaturas $(\mathrm{T})$ de formação dos minerais opacos, pode-se sugerir $\mathrm{T}$ iniciais de $950-900^{\circ} \mathrm{C}$, $\mathrm{T}$ de início de cristalização proposta por Dall'Agnol (1982) e Gastal (1987), respectivamente para os granitos Jamon e Musa, e T finais de $620-550^{\circ} \mathrm{C}$ (estágio subsolidus).

Certas diferenças entre os granitos Musa e Jamon foram observadas nos diagramas correlacionando SM e conteúdos minerais; tais diferenças podem estar relacionadas a pequenas peculiaridades da evolução de cada granito. Estes tipos de comportamento devem repetir-se em relação aos dados químicos. Entretanto, o número reduzido de amostras no Granito Musa que apresentam simultaneamente medidas de SM e dados químicos não permite comprovar essas variações em relação ao Granito Jamon, o qual define o comportamento esperado entre $\mathrm{SM}$ e os diversos óxidos $\left(\mathrm{Fe}_{2} \mathrm{O}_{3}, \mathrm{FeO}\right.$, $\mathrm{MgO}$ e $\mathrm{TiO}_{2}$ ).

CONCLUSÕES O Granito Musa foi subdividido em três populações magnéticas, as quais se correlacionam coeren- 

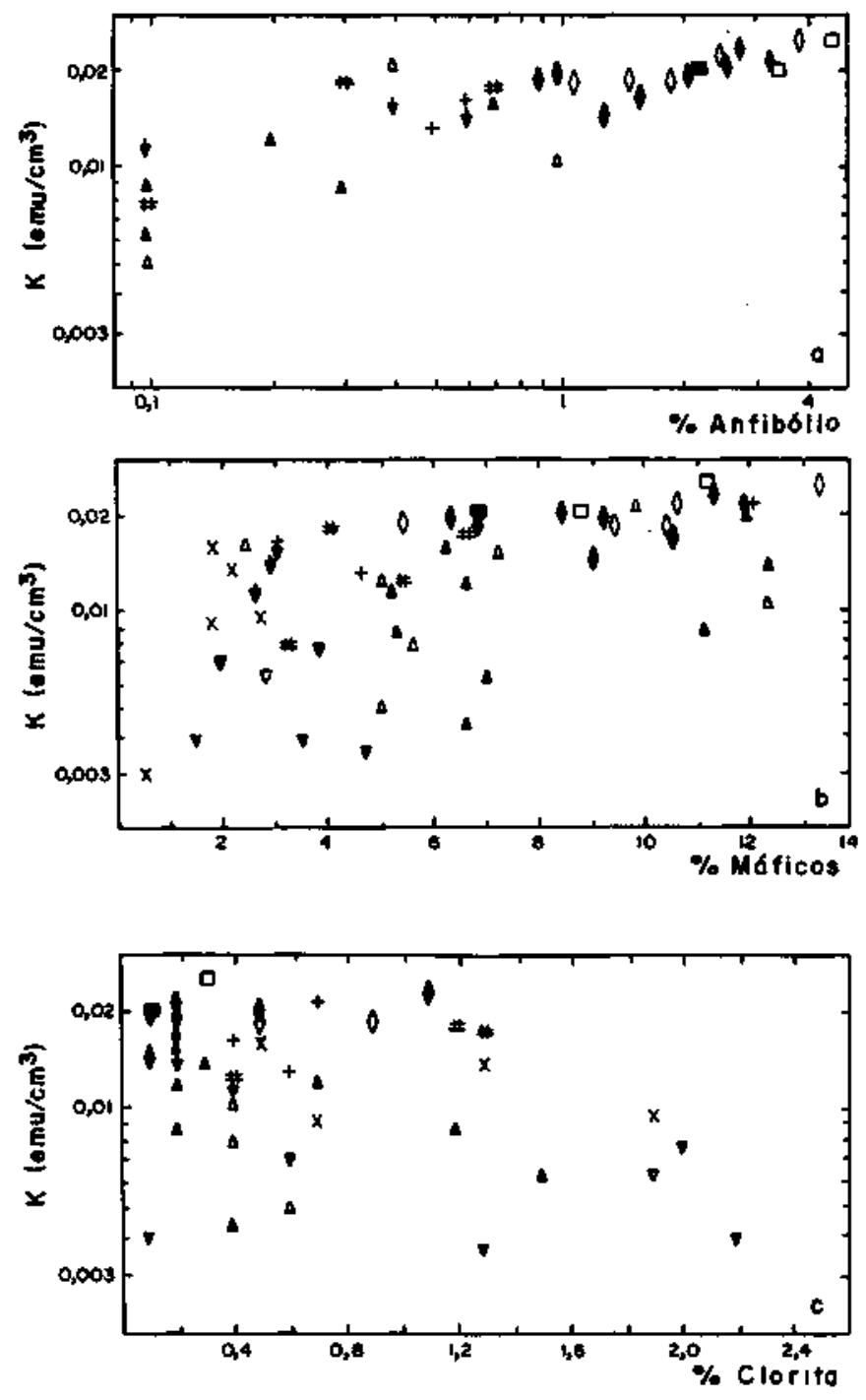

Figura 7 - Diagramas mostrando o comportamento de suscetibilidade magnética $(K)$ versus conteúdos de (a) anfibólio, (b) máficos e (c) clorita nas diversas fácies dos Granitos Musa e Jamon. Símbolos conforme figura 6

Figure 7 - Magnetic susceptibility (K) versus (a) amphibole, (b) the total of mafic, and (c) chlorite modal contents for Musa and Jamon granites. Symbols like in figure 6

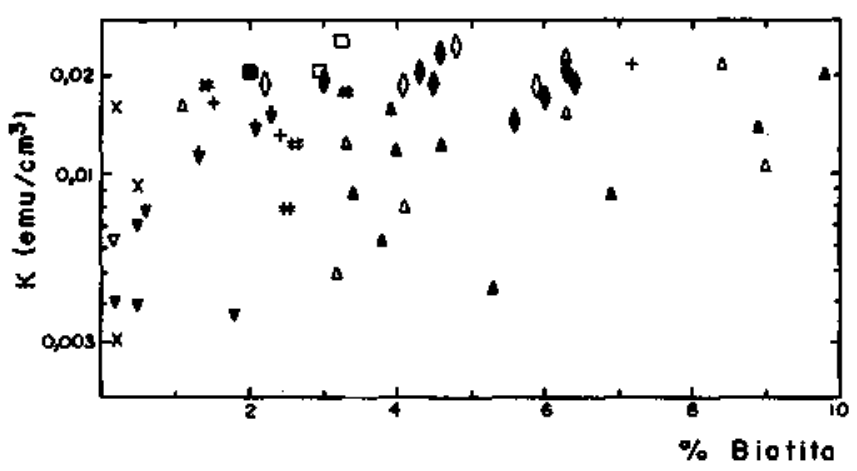

Figura 8-Diagrama mostrando o comportamento de susceiibilidade magnética $(K)$ versus conteúdo de biotita nas diversas fácies dos Granitos Musa e Jamon. Símbolos conforme figura 6

Figure 8 - Magnetic susceptibility (K) versus biotite modal contents plot for Musa and Jamon granites. Symbols like in figure 6 temente com as suas subfácies. As rochas formadas precocemente, relativamente ricas em hornblenda, possuem os maiores valores de SM (população " $C$ "), enquanto os leucogranitos, mais tardios, encontram-se distribuídos na população "A", que agrupa os menores valores de Sm. Os valores intermediários (populção "B”) são observados nas rochas com dominância de biotita $\mathrm{BM}, \mathrm{ABSH}, \mathrm{ABSG}, \mathrm{ABSP}$ - e em alguns leucogranitos, que se situam na porção inferior dessa população. $O$ Granito Jamon também foi subdividido em três
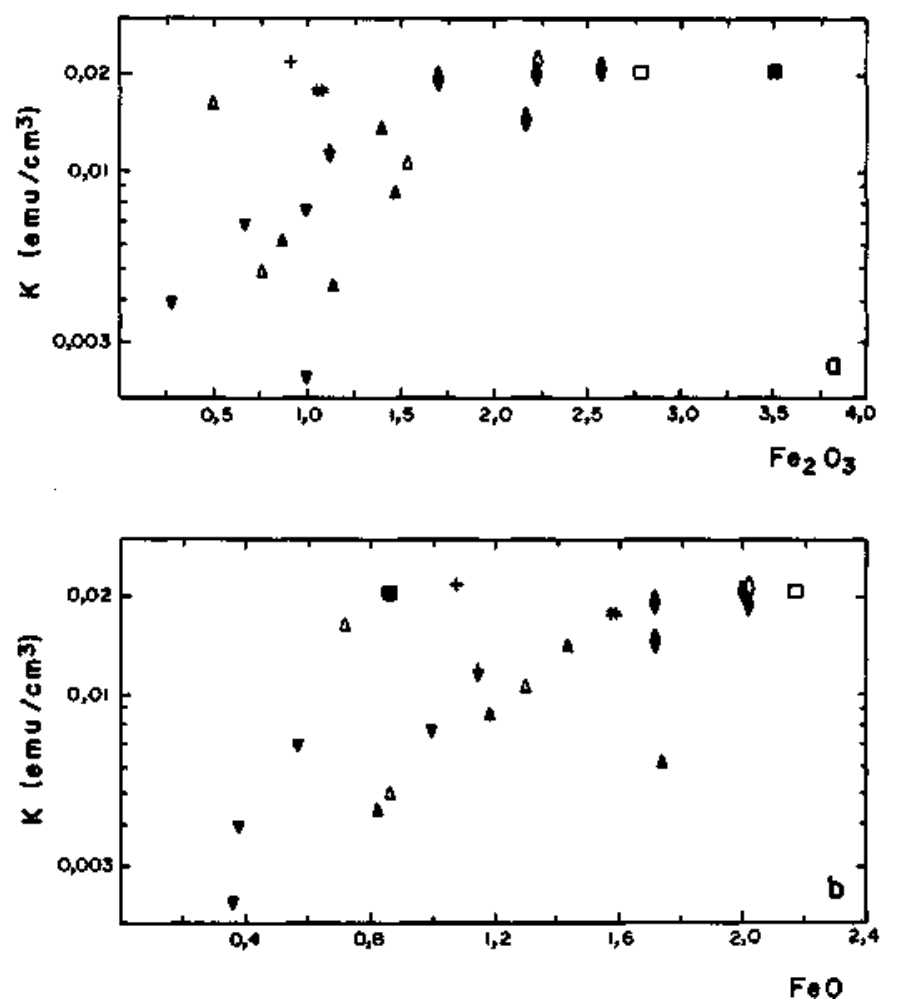

Figura 9 - Diagramas mostrando o comportamento de suscetibilidade magnética (K) versus \% em peso de (a) $\mathrm{Fe}_{2} \mathrm{O}_{3}$ e (b) $\mathrm{FeO}$ nas diversas fácies dos Granitos Musa e Jamon. Símbolos conforme figura 6

Figure 9 - Magnetic susceptibility (K) versus (a) $\mathrm{Fe}_{2} \mathrm{O}_{3}(\mathrm{Wt} \%$ ) and (b) $\mathrm{FeO}$ $(\mathrm{Wt} \%)$ for Musa and Jamon granites. Symbols like in figure 6

populações magnéticas que apresentam excelente correlação com as suas fácies, com a SM diminuindo no sentido da diferenciação magmática (BAM+ABM -> BM -> LM), analogamente ao observado no Granito Musa. No Granito Jamon, observa-se ainda a correlação da SM com as texturas de suas rochas. Os granitos equigranulares apresentam os maiores valores de SM, enquanto os heterogranulares se distribuem apenas na população "B", e os microgranitos constituem toda a população "A" e parte da "B". Esta relação entre os valores de $\mathrm{SM}$ e as texturas tanto pode ser conseqüência da formação precoce dos granitos equigranulares, quanto decorrência da distribuição mais uniforme dos cristais de magnetita em rochas com essa textura, permitindo assim valores de SM mais elevados do que aqueles obtidos em amostras heterogranulares ou com a granulação muito reduzida. Possivelmente, estes dois fatores devem ser importantes, como fazem supor a presença de ABSE do Granito Musa na população "C", enquanto os ABSG, ABSP e ABSH ocorrem na população "B" e a ocorrência de LM equigranulares do Granito Jamon com SM mais elevada que BM heterogranulares.

As relações entre os dados de SM e os conteúdos de minerais opacos e anfibólio permitiram observar uma correlação positiva entre essas variáveis, demonstrando o equilíbrio entre os opacos e anfibólio, minerais formados em estágio magmático 

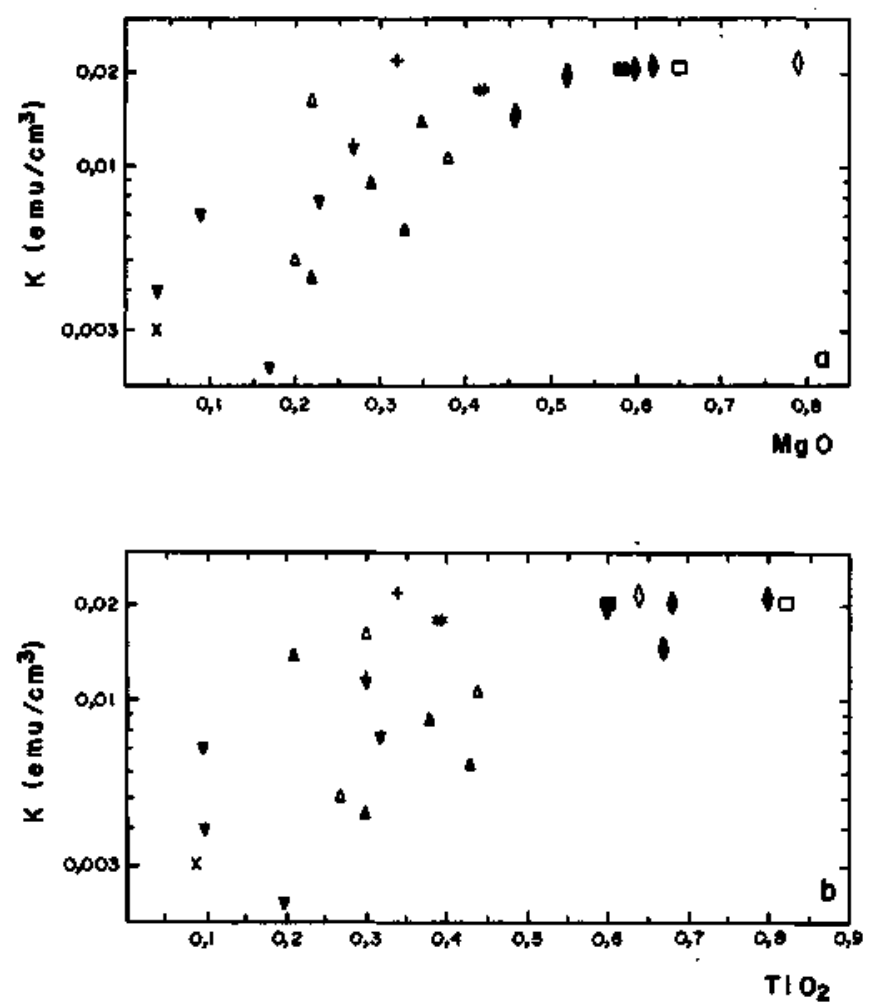

Figura 10 - Diagramas mostrando o comportamento de suscetibilidade magnética $(K)$ versus \% em peso de (a) $\mathrm{MgO}$ e (b) $\mathrm{TiO}_{2}$ nas diversas fácies dos granitos Musa e Jamon. Símbolos conforme figura 6

Figure 10 - Magnetic susceptibility (K) versus (a) $\mathrm{MgO}$ (wt\%) and (b) $\mathrm{TiO}_{2}$ (wt \%) for Musa and Jamon granites. Symbols like in figure 6

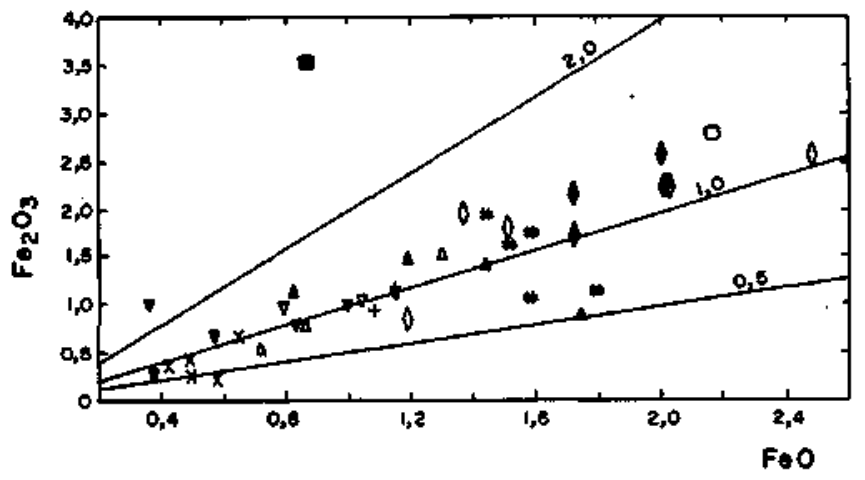

Figura 11 - Diagrama $\mathrm{Fe}_{2} \mathrm{O}_{3}$ (\% peso) versus $\mathrm{FeO}$ (\% peso) mostrando as variações do grau de oxidação nas diversas fácies dos granitos Musa e Jamon. Símbolos conforme figura 6 Figure $11-\mathrm{Fe}_{2} \mathrm{O}_{3}$ (wt\%) versus $\mathrm{FeO}(\mathrm{wt} \%$ ) plot, showing the oxidizing degree variation for Musa and Jamon granites. Symbols like in figure 6

precoce. Uma exceção a esse tipo de comportamento é a fácies LM do Granito Jamon, que, distintamente, mostra para conteúdos mais elevados de opacos os mais baixos valores de SM, sugerindo que, houve uma formação significativa de opacos diferentes de magnetita, possivelmente nos estágios evolutivos mais tardios. Por outro lado, entre SM e clorita observa-se uma correlação negativa, caracterizando a desestabilização e conseqüente hematitização de magnetita nos estágios tardi a pósmagmátícos nas variedades mais ricas em fluidos. Este comportamento é claro nas fácies cujo conteúdo de clorita é mais significativo (BM, LM, LS e MCS). O trend de diferenciação magmática também é marcado a partir da relação entre conteúdos de máficos e SM. Amostras mais enriquecidas em minerais ferromagnesianos, precoces no sentido da evolução magmática, possuem os maiores valores de SM, confirmando a formação de magnetita nos estágios iniciais da cristalização.

Uma correlação positiva entre biotita e SM parece existir, apenas, nas fácies a biotita dos dois maciços e nos LM do Granito Jamon. O porquê de tal comportamento ainda não se encontra esclarecido.

As correlações positivas observadas entre SM e óxidos de $\mathrm{Fe}^{3+}, \mathrm{Fe}^{2+}, \mathrm{Mg}^{2+}$ e $\mathrm{Ti}^{4+}$ traduzem o decréscimo desses óxidos e de SM durante a diferenciação magmática. As rochas formadas precocemente, cujos valores de SM são também os mais elevados, são enriquecidas nesses óxidos.

Condições oxidantes estiveram presentes durante a formação dessas rochas conforme sugerem as razões $\mathrm{Fe}_{2} \mathrm{O}_{3} / \mathrm{FeO}$ próximas a um $(1,0)$, a associação mineral titanita + magnetita + quartzo e os valores de SM relativamente elevados, em conseqüência dos conteúdos expressivos de magnetita. Tais características permitem classificar essas rochas como granitos da série a magnetita os quais, por sua vez, estão relacionados a condições oxidantes. Logo, acredita-se que $\mathrm{fO}_{2}$ próximas às do tampão Ni-NiO devem ter existido durante a cristalização desses granitos (cf. Whalen \& Chappell 1988, Wones 1989, Dall'Agnol et al. inédito). Com o avanço da diferenciação magmática, deve ter ocorrido um aumento relativo de $\mathrm{fO}_{2}$, no entanto os valores de SM são mais baixos, haja vista a redução do conteúdo de magnetita durante a diferenciação e a sua desestabilização parcial a hematita, nos estágios tardi a pós-magmáticos.

Agradecimentos Este trabalho é baseado em uma parte da dissertação de mestrado desenvolvida por um dos autores (M.S. Magalhães) no curso de Pós-graduação em Geociências (área: Geoquímica e Petrologia) da Universidade Federal do Pará - UFPA.

Gostaríamos de agradecer a William A. Sauck (UFPA/ Western Michigan University), José Gouvêa Luiz (UFPA) e Márcia Ernesto (IAG - Universidade de São Paulo) pelas discussões metodológicas referentes ao estudo magnético, ao Centre de Recherches Pétrographiques et Geochimiques - CRPG (Vandoeuvre, França) e ao laboratório de MicroAnalyses de Faculte de Sciences de Nancy pela utilização do $\mathrm{MEV}$, a M. Pichavant pelas discussões mantidas durante o pósdoutorado de um dos autores (R. Dall'Agnol) no CRPG, ao Sr. A. Kohler (CRPG) pelo auxílio no MEV e a J. Gorau (CRPG) pelas fotografias.

$\mathrm{O}$ suporte financeiro foi fornecido pelo PADCT/FINEP através do Projeto Petrologia dos Granitóides da Amazônia Oriental (4/3/87/0911/00), pelo Conselho Nacional de Desenvolvimento Científico e Tecnológico - CNPq e pela CAPESPADCT, que concederam as bolsas de mestrado e pós-doutorado, respectivamente.

\section{REFERÊNCIAS BIBLIOGRÁFICAS}

ALTHOFF, F.J.; DALL'AGNOL, R.; SOUZA, Z.S. 1991. Região de Marajoara - SE do Pará: prolongamento dos terrenos arqueanos de Rio Maria ou retrabalhamento? In: SIMP. GEOL. AMAZ., 3. Belém, 1991. Anais. Belém, SBG. p. 130-141.

ANDERSON, J.L. 1983. Proterozoic anorogenic granite plutonism of North America. In: MEDARIS, L.G., Jr.; BYERS, C. W.; MICKELSON, D. M.; SHANKS, W.C. eds. Proterozoic Geology: Selected Papers from an International Symposium. Boulder, Geol. Soc. Amer. p. 133-154.
ANDERSON, J.L. \& BENDER, E.E. 1989. Nature and origin of Proterozoic A- type granitic magmatism in the sothwestern United States of America Uthos, 23:19-52.

BARRIERE, M. \& GOTTEN, J. 1979. Biotites and associated minerals as markers of magmatic gractionation and deuteric equilibration in granites. Contrib. Mineral. Petrol., 70:183-192.

BUDDINGTON, A.F. \& LINDSLEY, D.H. 1964. Iron-titanium oxide minerals and synthetic equivalents. J. Petrol., 5(2):310-357. 
CARMICHAEL, R.S. 1986. Magnetic properties of minerals and rocks. In CARMICHAEL, R.S. Handbook of Physical Properties of Rocks. $2^{\text {nd }}$ ed. CRC Press, v. 2, p. 229-287.

CHAPPELL, B.W. \& WHITE, A. J.R. 1974. Two contrasting granite types. Pacific Geology, 8:173-174.

CORDEIRO, A.A.C.; ALVES, C.A.; FONSECA, L.R. 1982. Geologia da região da Serra dos Gradaús. In: SIMP. GEOL. DA AMAZÔNIA, 1. Belém, 1982. Anais... Belém, SBG. v.1, p. 50-53.

CORDEIRO, A.A.C.; ALVES, C.A.; FONSECA, L.R.; NASCIMENTO, J.A.S.; AZEVEDO, I.L.; SANTOS, F.F. 1984. Pesquisa geológica da jazida de wolframita de Pedra Preta, Rio Maria - PA. In: SYMP. AMAZ., 2. Manaus, 1984. Anais... Manaus, MME-DNPM. p. 375-379.

CRISS, R.E. \& CHAMPION, D.E. 1984. Magnetic properties of granitic rocks from southern half of Idaho Batholith: influences of hydrothermal alteration an implications for aeromagnetic interpretation. J. Geophys. Res., 89(B8):7061-7076.

CZAMANSKE, G.K. \& WONES, D.R. 1973. Oxidation during magmatic differentiation, Finnmarka Complex, Oslo Area, Norway: part 2, the mafic silicates. J. Petrol, 14(3):349-380.

DALL'AGNOL, R. 1980. Etudes sur des granites du type Rondonian en Amazonie Orientale et leurs transformations tardi-raagmatiques. Toulosse. 348 p. (These Troisime, cycle Univ. Paul Sabatier-Labor. Geol. Petrol.).

DALL'AGNOL, R. 1982. Maciço Jamon: evolução perológica de um granito da Amazônia Oriental. In: SIMP. GEOL. AMAZÔNIA, 1. Belém, 1982. Anais... Belém, SBG. v. 2, p. 139-161.

DALL'AGNOL, R. 1987. Petrologic evolution of the magnetite-bearing anorogenic Jamon Granite, East Amazon, Brazil: an example of moderate fractional crystallization. In: INTERNATIONAL SYMPOSIUM OF GRANITES AND ASSOCIATED MINERALIZATIONS (ISGAM). Salvador, 1987. Extended Abstracts... Salvador, SGM. p. 217-219.

DALUAGNOL, R.; BETTENCOURT, J.S.; JORGE JOÃO, X.S.; MEDEIROS, H.; COSTI, H.T.; MACAMBIRA, M.J.B. 1987. Granitogenesis in the Northern Brazilian Region: a review. Rev. Bras. Geoc., 17(4):382-403.

DALL'AGNOL, R.; SAUCK, W.A.; GONÇALEZ, M.G.B. 1988. Suscetibilidade magnética em granitóides da Amazônia: um estudo preliminar. In: CONOR. BRAS. GEOL., 35. Belém, 1988. Anais... Belém, SBG, v. 3 , p. 1164-1173.

DALL'AGNOL, R.; SCHUCKAMNN, W.K.; BASEI, M.A.S.; SCHELLER. T. 1984. Novos dados gcocronológicos e estudo de elementos traços de maciços graníticos anorogênicos da Amazônia Oriental, Estado do Pará (Brasil). In: SYMP. AMAZ., 2. Manaus, 1984. Anais... Manaus, MMEDNPM. p. 59-74.

DALL'AGNOL, R.; VIEIRA, E.A.P.; SÁ, C.A.S.; MEDEIROS, H.; GASTAL, M.C.P.; TEIXEIRA, N.P. 1986. Estado atual do conhecimento sobre as rochas granitóides da porção sul da Amazônia Oriental. Rev. Bras. Geoc., 16(1): 11-23.

DOCEGEO 1988. Revisão litoestratigráfica da Província Mineral de Carajás. In: CONOR. BRAS. GEOL., 35. Belém, 1988. Anexo aos Anais.. Belém, SBG. p. 11-54.

GASTAL, M.C.P. 1987. Mapeamento e Petrologia do Maciço Granítico Musa: Rio Maria, Sudeste do Pará. Belém. 319 p. (Tese de Mestrado, UFPA-Centro de Geociências).

GASTAL, M.C.P. 1988. Magmatismo ácido-intermediário do Proterozóico Médio na região de Rio Maria, SE do Pará: discussão quanto à tipologia. In: CONOR. BRAS. GEOL., 35. Belém, 1988. Anais... Belém, SBG. v. 3. p. $1147-1163$.

GASTAL, M.C.P.; MACAMBIRA, M.J.B.; MEDEIROS, H.; DALL'AGNOL, R. 1987. Idades e geoquímica isotópica Rb-Sr do Granito Musa e Granodiorito Rio Maria, Amazônia Oriental. Geoq. Bras., I(2):247-259.

GRANT, F.S. 1985. Aeromagnetics, geology and ore environments. I. Magnetite in igneous, sedimentary and metamorphic rocks: an overview. Geoexploration, 23:303-333

HAGGERTY. S.E. 1979. The aeromagnetic mineralogy of igneous rocks. Can. J. Earth Sci., 16:1281-1293.

HAGGERTY, S.E. 198 la. Oxidation of opaque mineral oxides in bassalts. In: RUMBLE m, D. ed. Oxide Minerals. 2 ed. Washington, Miner. Soc. Am. p. 1-99. (Short course notes).

HAGGERTY, S.E. 1981b. Opaque mineral oxides in terrestrial igneous rocks. In: RUMBLE m, D. ed. Oxide Minerals. 2 ed. Washington, Miner. Soc. Am. p. 101-300. (Short course notes).

HATTORI, K. 1987. Magnetic felsic intrusions associated with Canadian Archean gold deposits. Geology, 15:1107-1111.
HOOD, P.J.; HOLROYD, M.T.; McGRATH, P.H. 1979. Magnetic methods applied to base metal exploration. In: HOOD, P.J. ed. Geophysics and Geochemistry in the Search for Metallic Ores. Canadá, Geol. Survey Canada, Econ. Geol. p. 77-104. (Report. 31).

HUHN, S.R.B.; SANTOS, A.B.S.; AMARAL, A.F.; LEDSHAM, E.J.; GOUVÓA, J.L.; MARTINS, L.P.B.; MONTALVO, R.M.G.; COSTA V.G. 1988.0 terreno "granite-greenstone" da Região de Rio Maria - Sul do Pará. In: CONGR.BRAS.GEOL., 35. Belém, 1988. Anais... Belém, SBG. v. 3, p. 1438-1452.

ISHIHARA, S. 1977. The magnetite-series and ilmenire-series granitic rocks. Mining Geology, 27:293-305.

ISHIHARA, S. 1981. The granitoid series and mineralization. In: SKINNER. B. J. ed. Economic Geology Seventy-fifth Anniversary-volume. p. $458-484$.

LAPOINTE, P.; MORRIS, W. A.; HARDING, K.L. 1986. Interpretation of magnetic susceptibility: a new approach to geophysical evaluation of the degree of rock alteration. Can. J. Earth Sci. 23:393-401.

LARSSON, L.O. 1977. Statistical treatment of in-situ meassurements of magnetic susceptibility. Sveriges Geologiska Undersohting, C727:3-22.

LJNDSLEY, D.H. 1981. Some experiments pertaining to the magnetiteUlvospinel miscibility gap. Am. Mineral., 66:759-762.

MACHADO, N.; LJNDENMAYER, D.; LINDENMAYER, Z. 1988. Geocronologia U-Pb da Província Metalogenética de Carajás, Pará resultados preliminares. In: CONOR. LAT. AMER. GEOL., 7. Belém, 1988. Anais... Belém, SBG. v. 1, p. 339-347.

MAGALHÃES. M.S. 1991. Minerais Opacos e Susceptibilidade Magnética de Granitóides da Amazônia Oriental: Implicações Petrológicas. Belém. 274 p. (Dissertação de Mestrado, Centro de Geociências, UFPA).

MAGALHÃ̃ES, M.S. \& DALL'AGNOL, R. 1991. Considerações petrológicas baseadas em estudos de minerais opacos e suscetibilidade magnética no Granodiorito Rio Maria (região de Rio Maria - sudeste do Pará). In: SIMP GEOL. AMAZ, 3. Belém, 1991. Anais... Belém, SBG. p. 70-84.

McGRATH, P.H. 1970. Magnetic investigations of Charlotte and Poliok Intrusions. Southern New Brunswick. In: THE GEOL. ASS. CANADA, Proceedings, 21:25-32.

MEDEIROS, H.; GASTAL, M.C.P · DALL'AGNOL, R · SOUZA, Z.S. 1987. Geology of the Rio Maria area (Eastern Amazonian Region - Brazil): an example of Archean granite-greenstone terrane intruded by anorogenic granites of Middle Proterozoic ages. In: FINAL MEETING OF THE WORKING GROUP PROJECT 204. Carajás, 1987. Extended Abstracts... Carajás, IGCP. p. 97-109.

MOONEY, H.M. \& BLEEFUSS, R. 1953. Magnetic susceptibility measurements in Minnesota, part H, analysis of field results. Geophysics, 18:383-393

PITCHER, W.S. 1983. Granite tipology, geological environment and melting relationships. In: ATHERTON, M.P. \& GRIBBLE, C.D. ed. Migmatites, Melting and Metamorphism. S.I., Shiva Publ. p. 277-285.

PRICE, G.D. 1981. Subsolidus phase relations in the titanomagnetite soid solution seires. Am. Mineral., 66:751-758.

ROKOV, A.N. \& SOLOV'YEV, G.A. 1971. Use of detailed petrophysical investigations for studying the structures of hydrothermal deposits. Geophys. Abstr., 296:1211.

SOUZA, Z.S.; MEDEIROS, H.; ALTHOFF, F.J.; DALL'AGNOL, R. 1990. Geologia do terreno granito-"greenstone" Arqueano da região de Rio Maria, sudeste do Pará. In: CONOR. BRAS. GEOL., 36. Natal, 1990. Anais... Natal, SBG. v. 6. p. 2913-1928.

SPENCER, KJ. \& LINDSLEY, D.H. 1981. A solution model for coexisting iron-titanium oxides. Am. Mineral., 66:1189-1201.

TARLING, D.H. 1971. Principles and Application of Paleomagnetism London, Chapman and Hall. $164 \mathrm{p}$.

WHALEN, J.B. \& CHAPPELL, B.W. 1988. Opaque mineralogy and mafic mineral chemistry of I- and S-type granites of the Lachlan fold belt, southeast Australia. Am. Mineral., 73:281-296.

WHITE, A.J.R. \& CHAPPELL, B.W. 1977. Ultrametamorphism and granitoid genesis. Tectonophysics, 43:7-22.

WONES, D.R. 1989. Significance of the assemblage titanite+magnetite+ quartz in granitic rocks. Am. Mineral, 74:744-749.

Manuscrito A714 Recebido em 20 de janeiro de 1992 Revisão do autor em 26 de maio de 1992 Revisão aceita em 28 de maio de 1992 